Supplement of The Cryosphere Discuss., 9, 2655-2707, 2015

http://www.the-cryosphere-discuss.net/9/2655/2015/

doi:10.5194/tcd-9-2655-2015-supplement

(C) Author(s) 2015. CC Attribution 3.0 License.

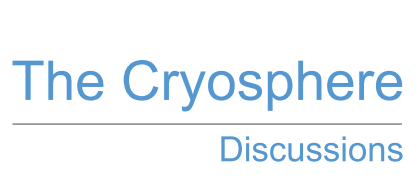

(c) (1)

Supplement of

\title{
Verification of the multi-layer SNOWPACK model with different water transport schemes
}

N. Wever et al.

Correspondence to: N. Wever (wever@slf.ch) 


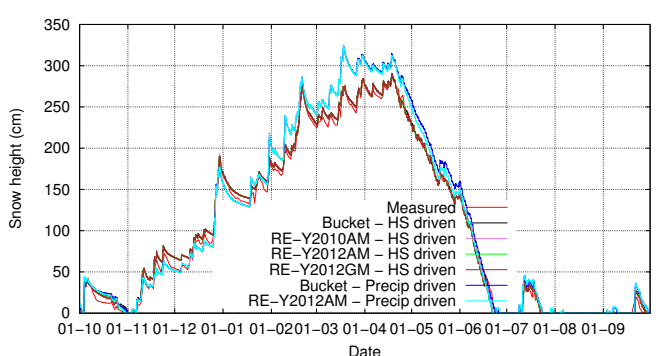

(a) $1999-2000$

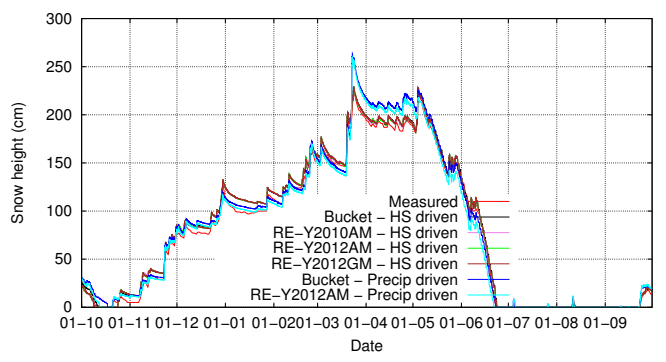

(c) 2001-2002

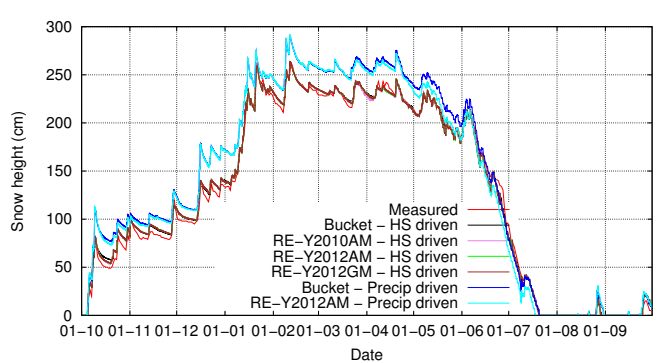

(e) $2003-2004$

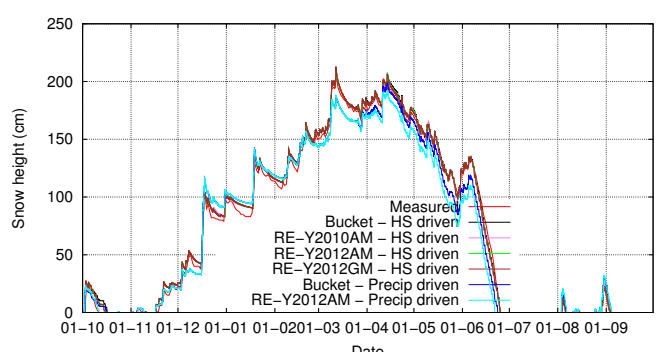

(g) $2005-2006$

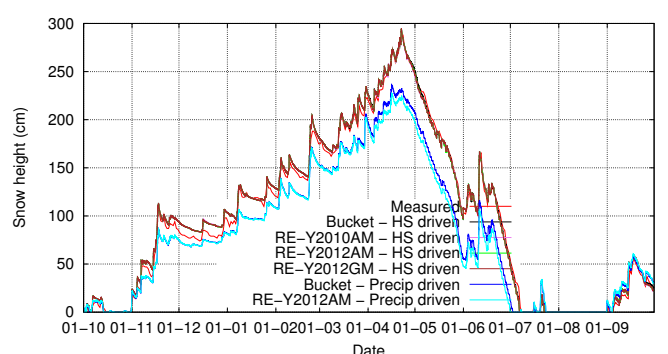

(b) $2000-2001$

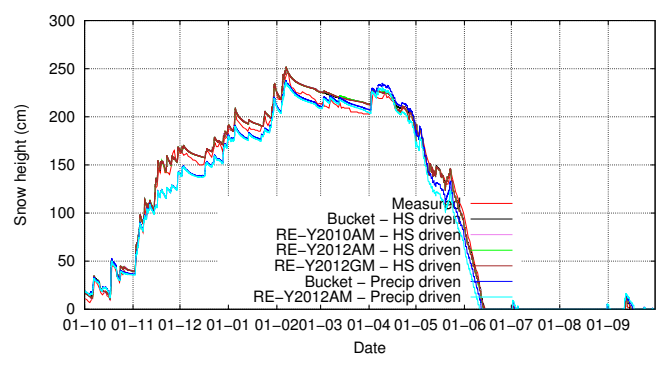

(d) $2002-2003$

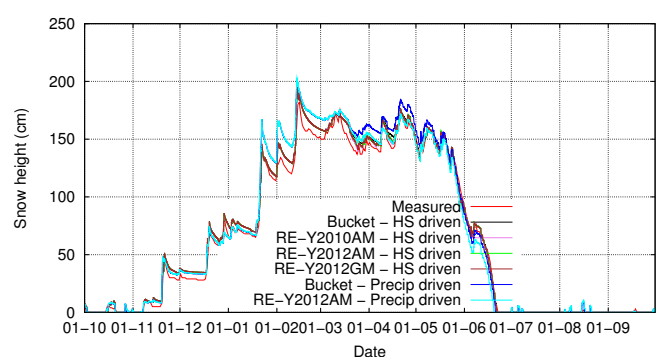

(f) $2004-2005$

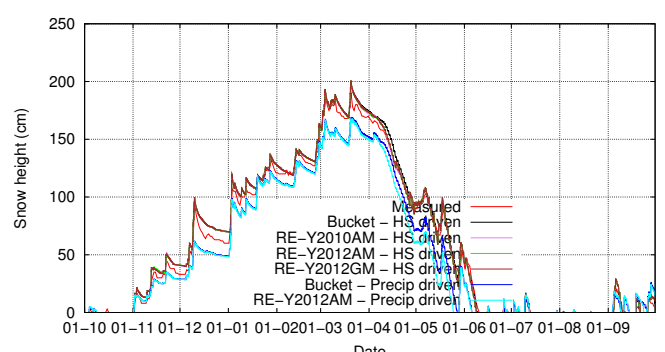

(h) 2006-2007

Figure S1: Measured and modelled snow height for different model setups. 


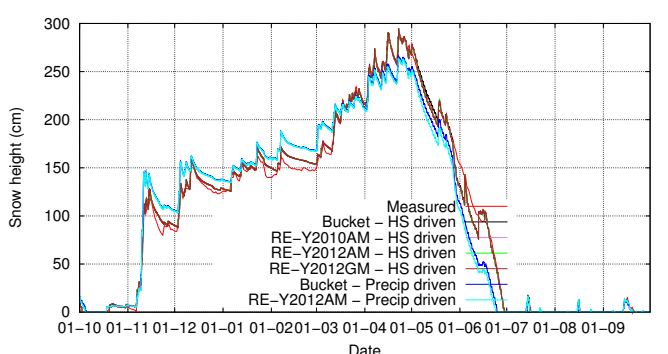

(a) $2007-2008$

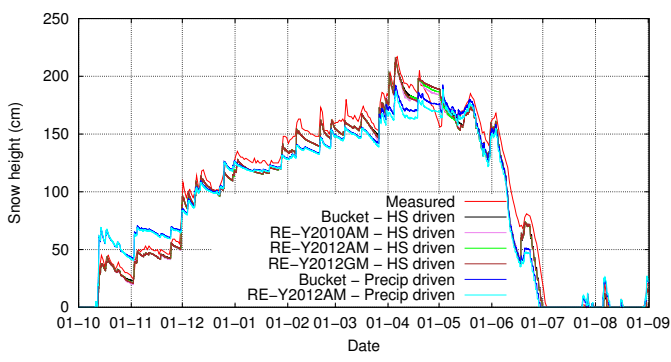

(c) $2009-2010$

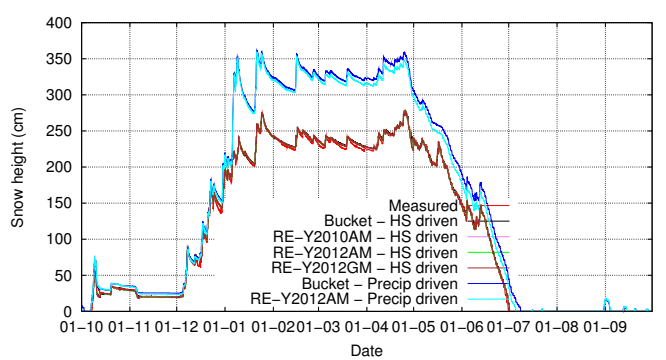

(e) 2011-2012

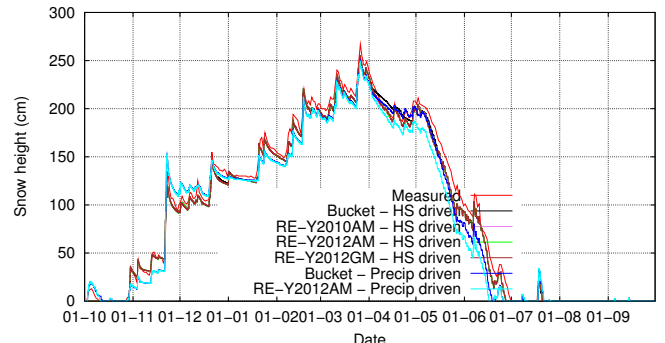

(b) $2008-2009$

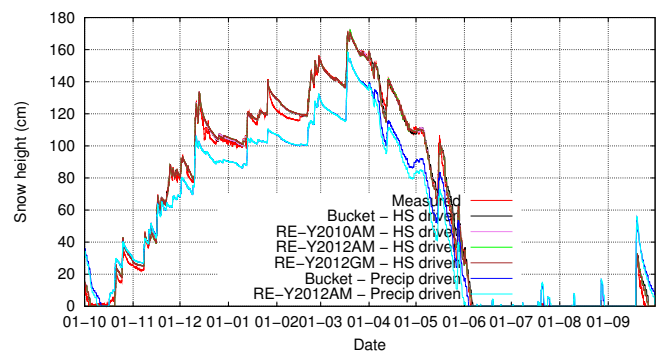

(d) $2010-2011$

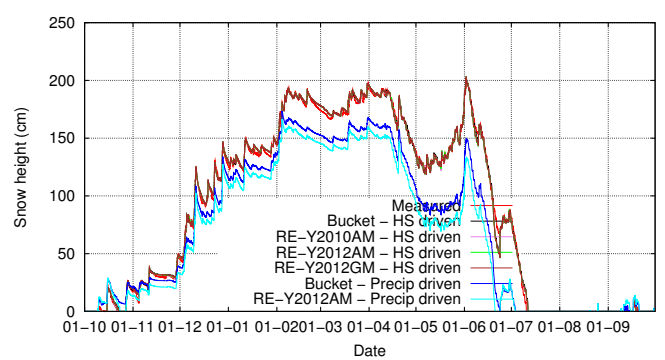

(f) 2012-2013

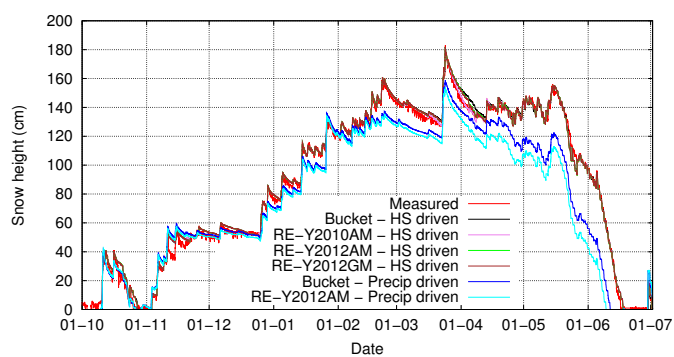

(g) 2013-2014

Figure S2: Measured and modelled snow height for different model setups, continued. 


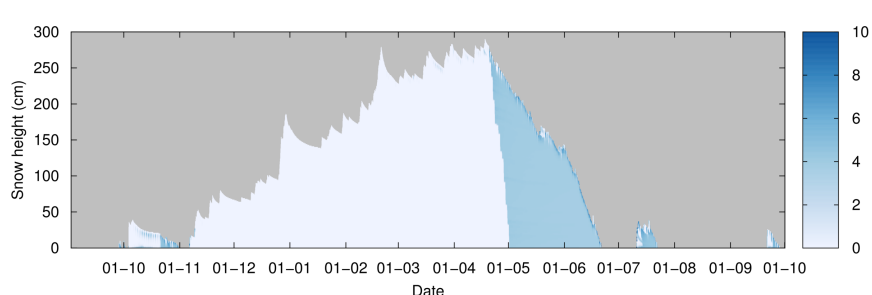

(a) $1999-2000$

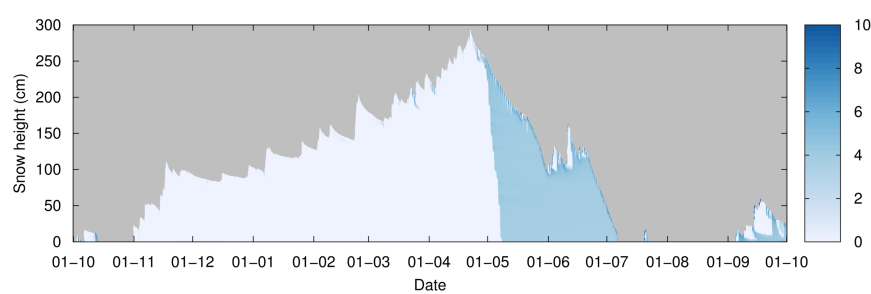

(c) $2000-2001$

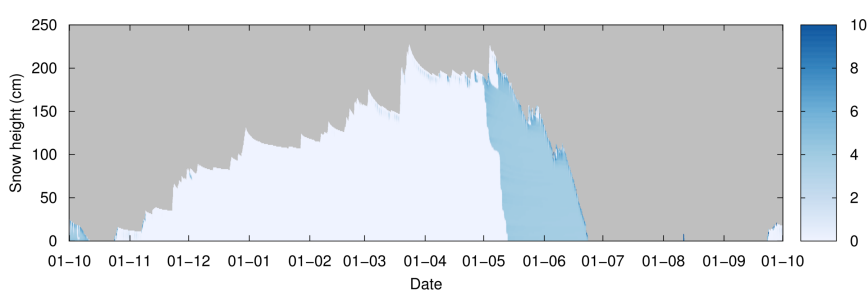

(e) 2001-2002

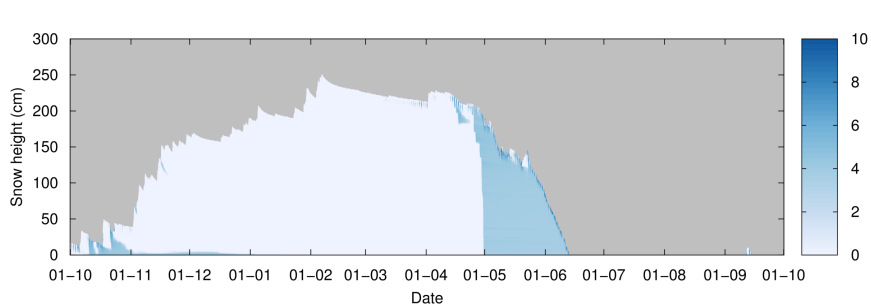

(g) 2002-2003

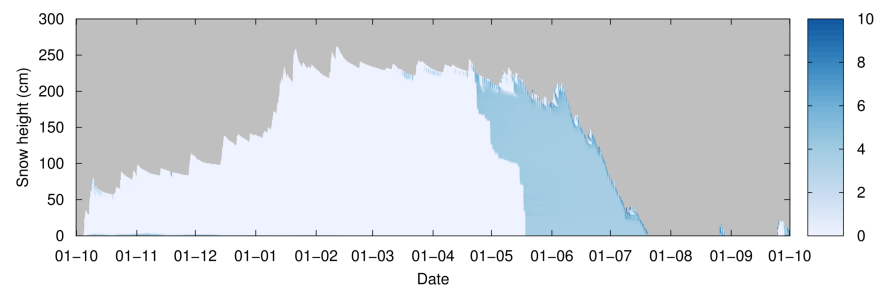

(i) 2003-2004

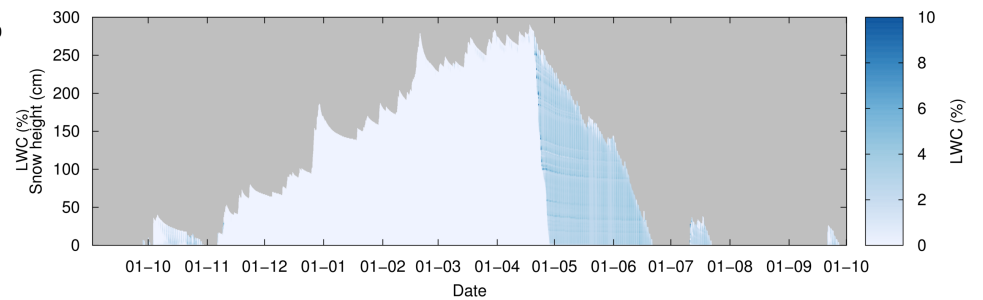

(b) $1999-2000$

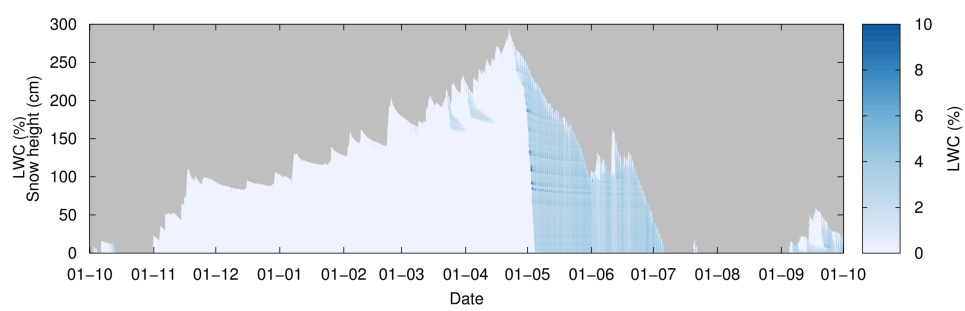

(d) $2000-2001$

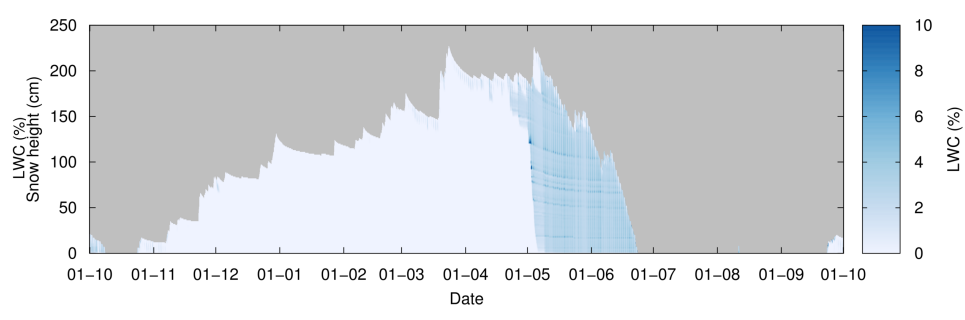

(f) $2001-2002$

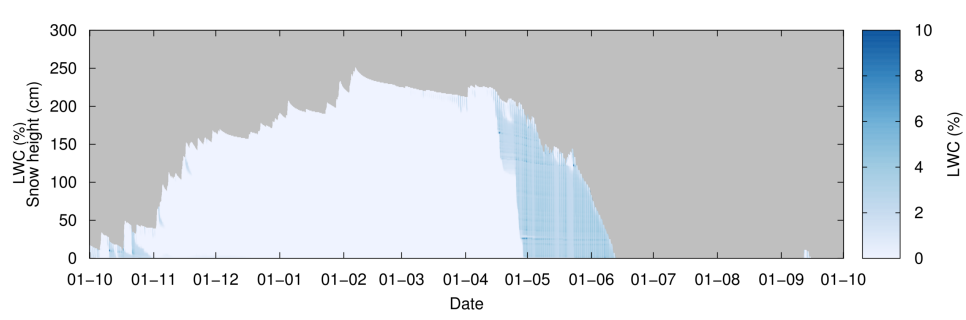

(h) $2002-2003$

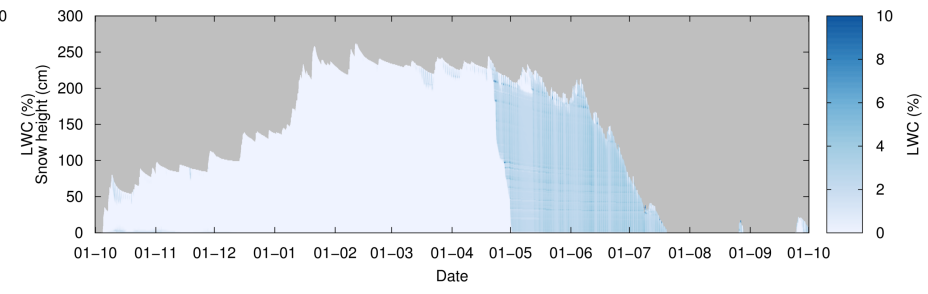

(j) 2003-2004

Figure S3: LWC (\%) for the snow height-driven simulations with the bucket scheme (left), and with RE-Y2012AM (right). 


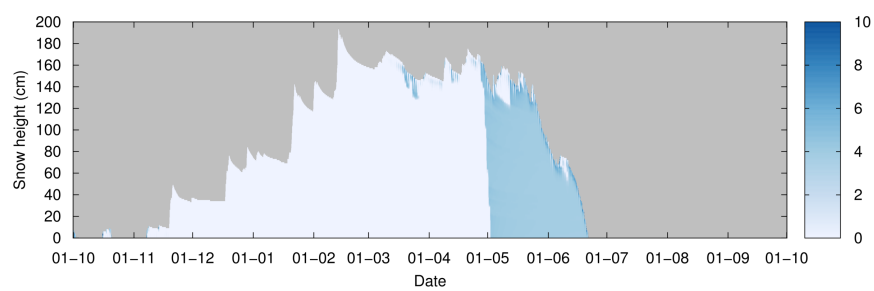

(a) 2004-2005

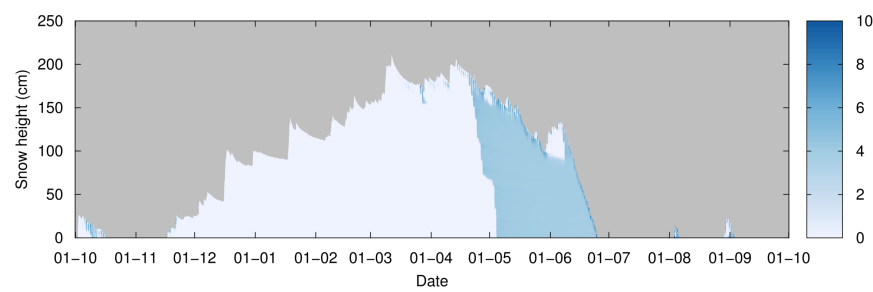

(c) $2005-2006$

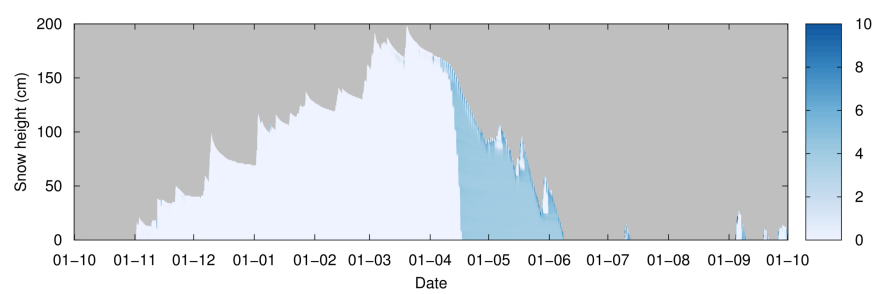

(e) 2006-2007

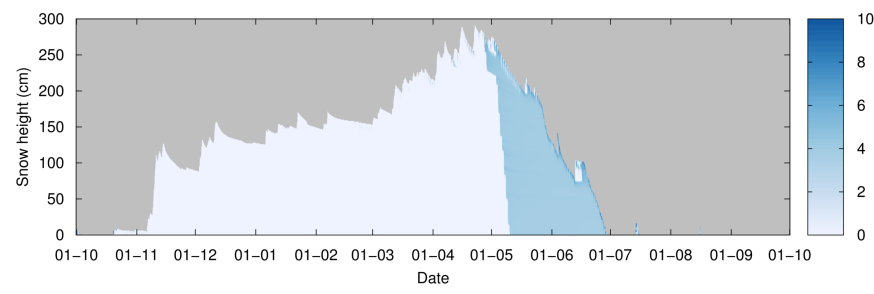

(g) $2007-2008$

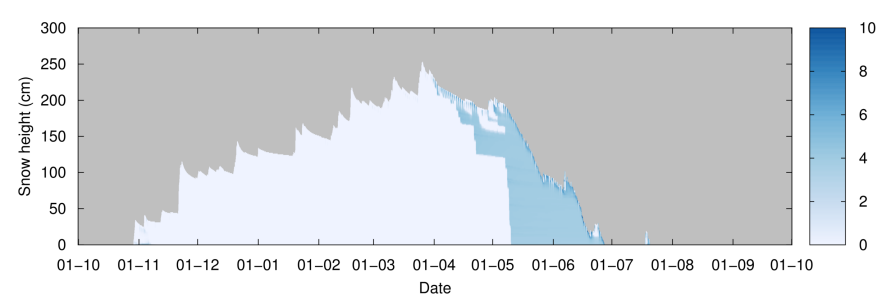

(i) 2008-2009

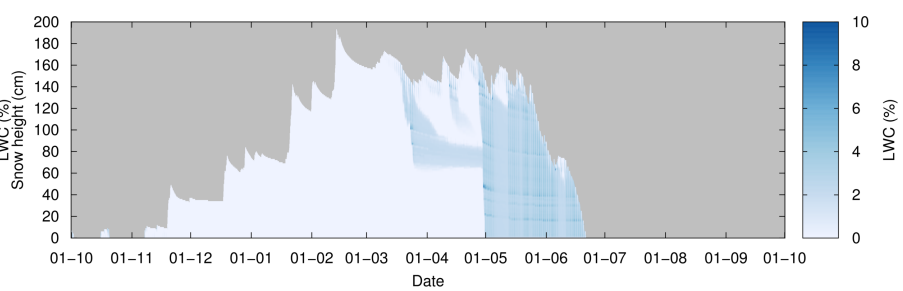

(b) 2004-2005

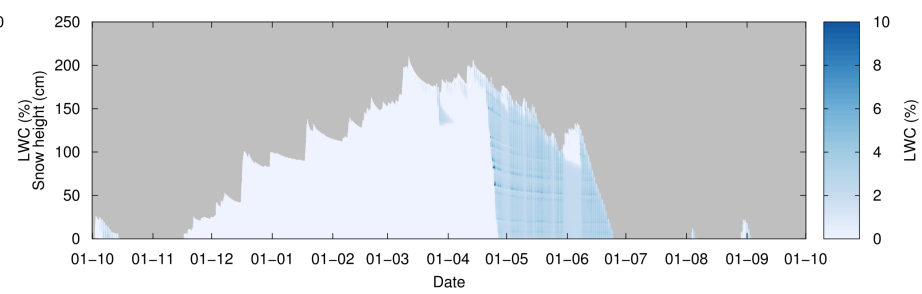

(d) 2005-2006

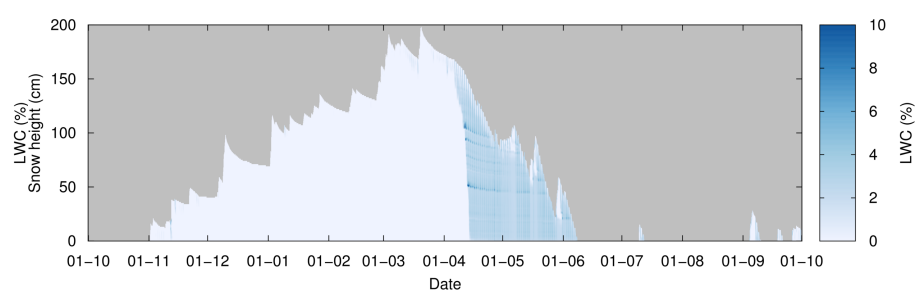

(f) 2006-2007

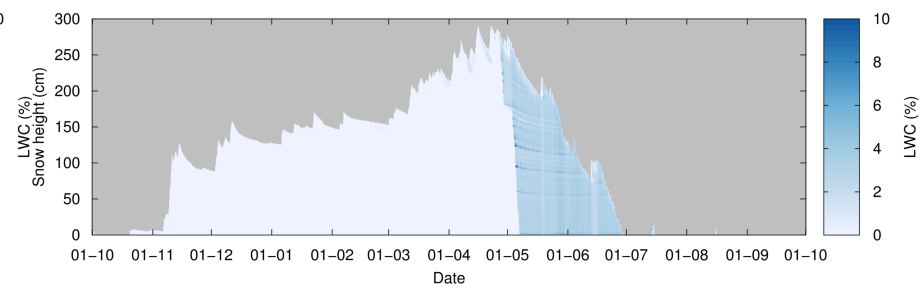

(h) 2007-2008

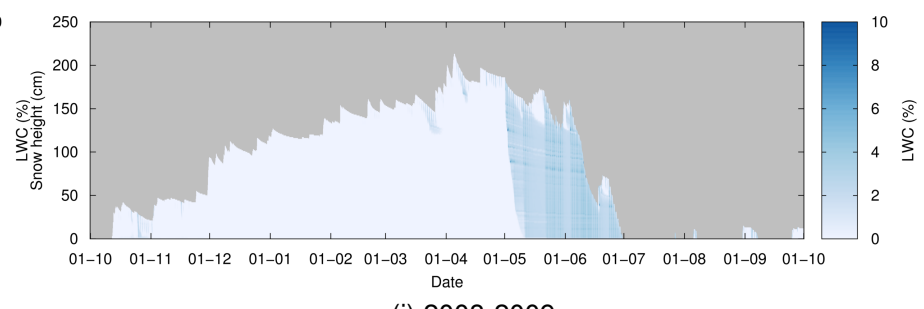

(j) 2008-2009

Figure S4: LWC (\%) for the snow height-driven simulations with the bucket scheme (left), and with RE-Y2012AM (right), continued. 


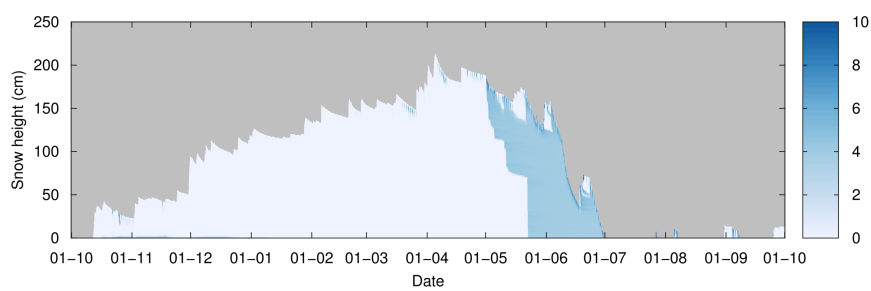

(a) $2009-2010$

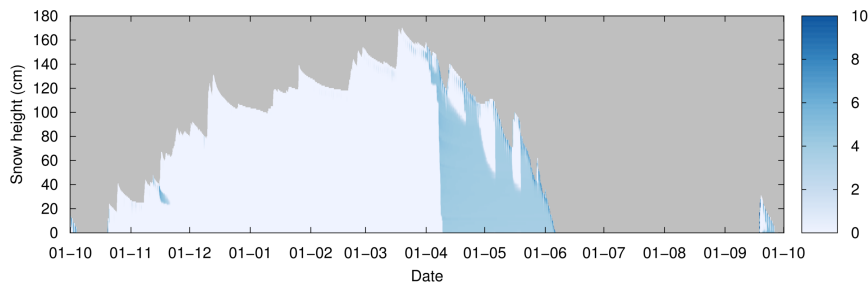

(c) $2010-2011$

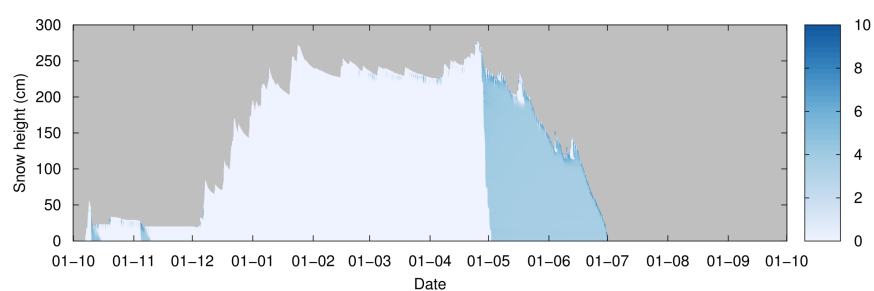

(e) 2011-2012

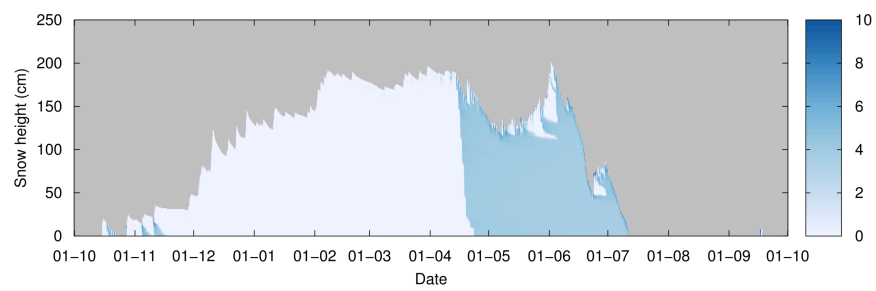

(g) $2012-2013$

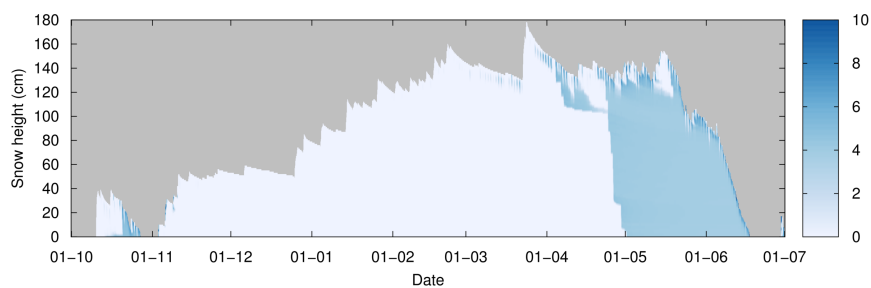

(i) $2013-2014$

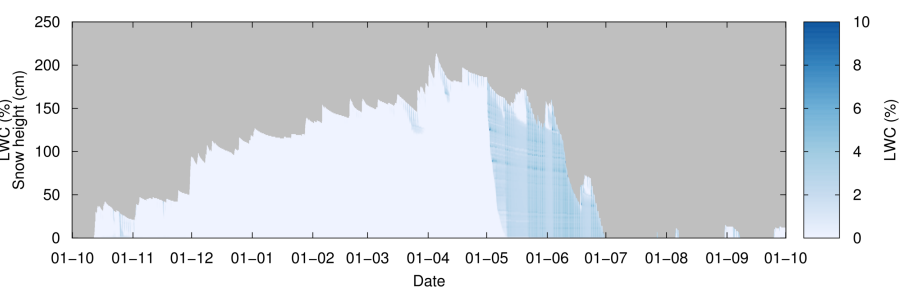

(b) 2009-2010

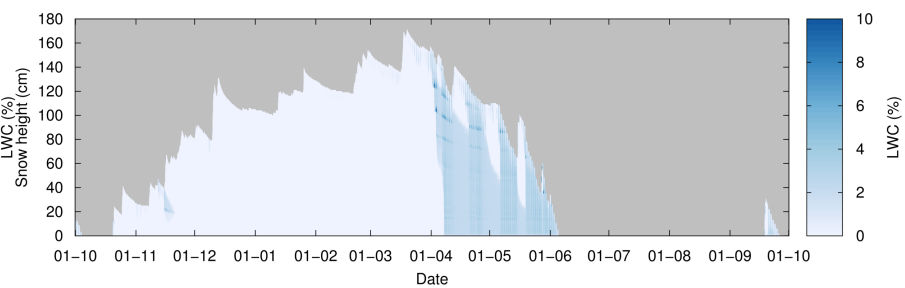

(d) $2010-2011$

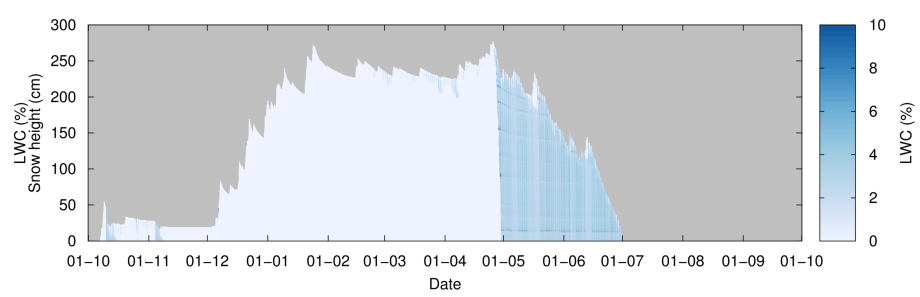

(f) 2011-2012

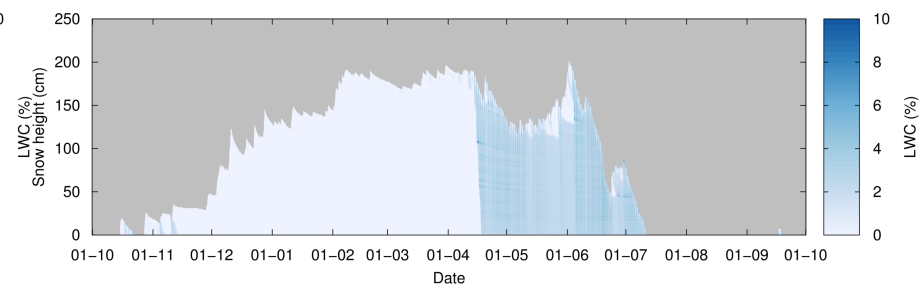

(h) 2012-2013

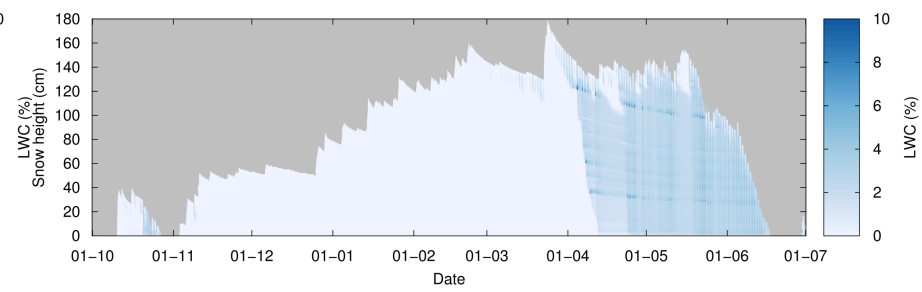

(j) 2013-2014

Figure S5: LWC (\%) for the simulations with the bucket scheme (left), and with RE-Y2012AM (right), continued. 


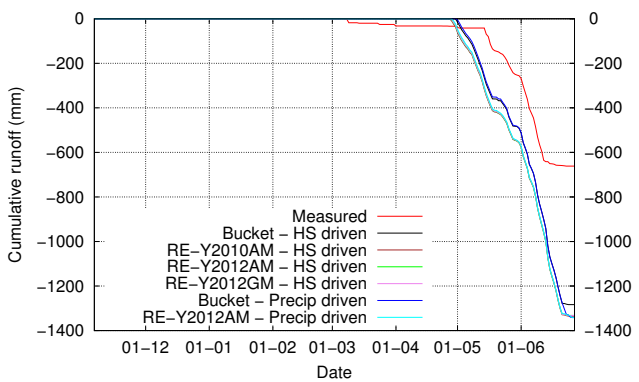

(a) $1999-2000$

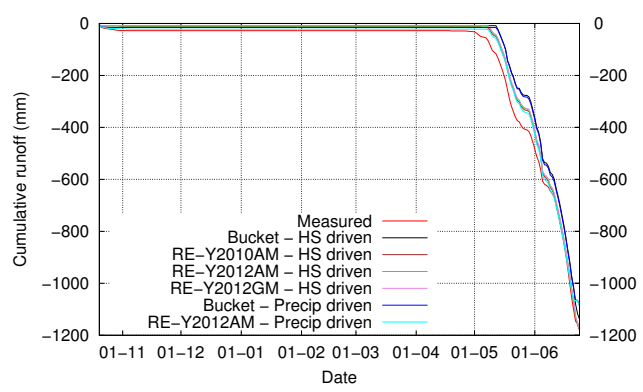

(c) 2001-2002

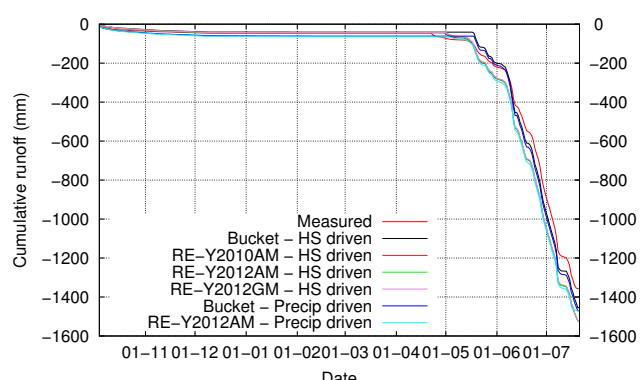

(e) 2003-2004

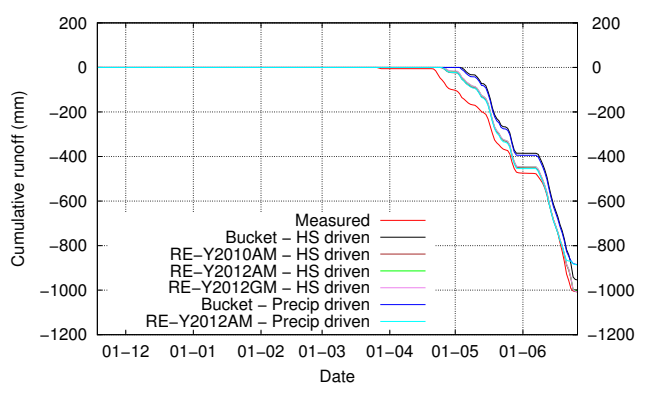

(g) $2005-2006$

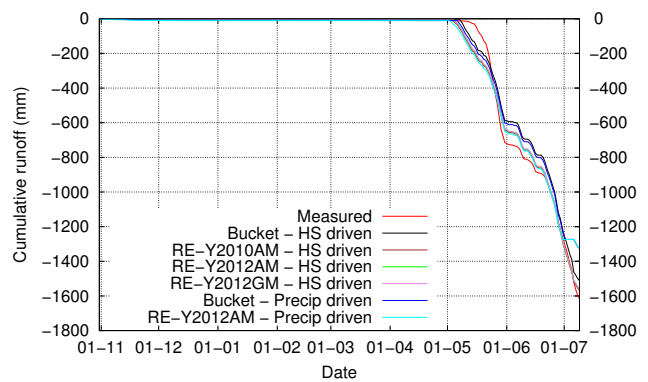

(b) $2000-2001$

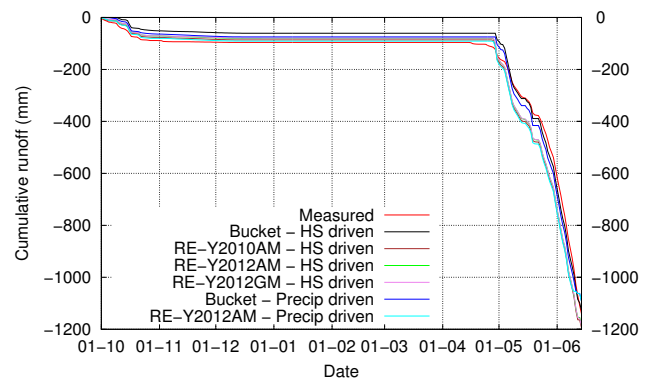

(d) $2002-2003$

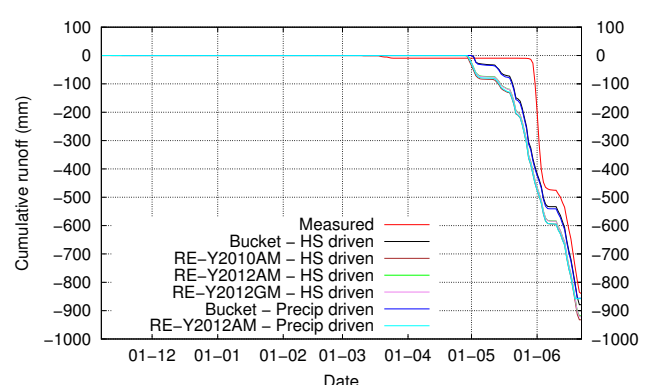

(f) 2004-2005

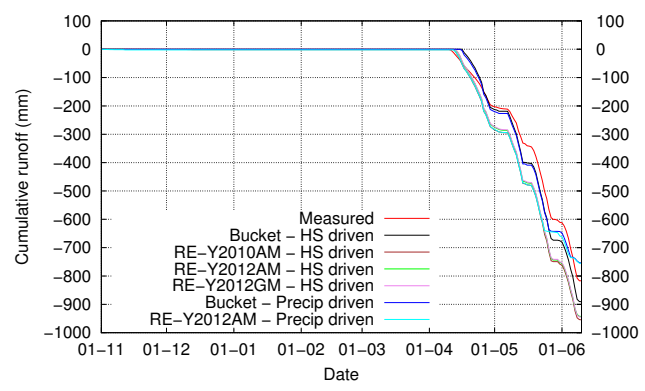

(h) 2006-2007

Figure S6: Cumulative runoff $(\mathrm{mm})$. 


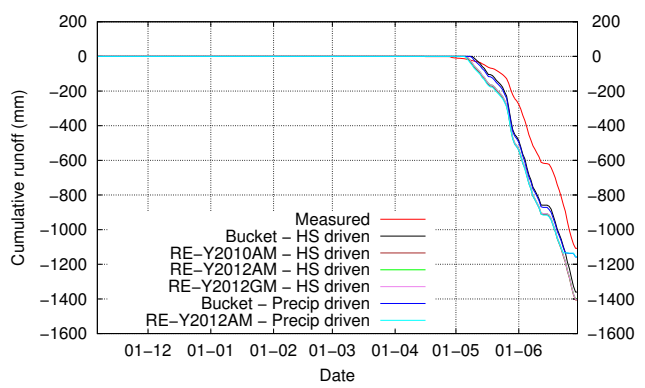

(a) $2007-2008$

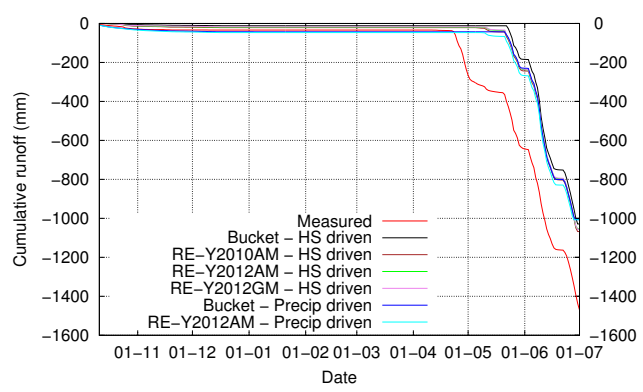

(c) $2009-2010$

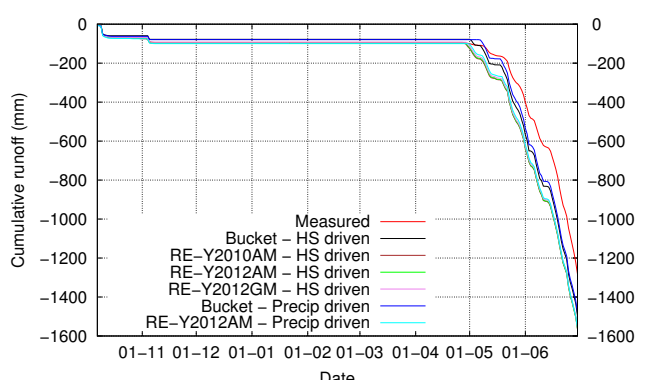

(e) 2011-2012

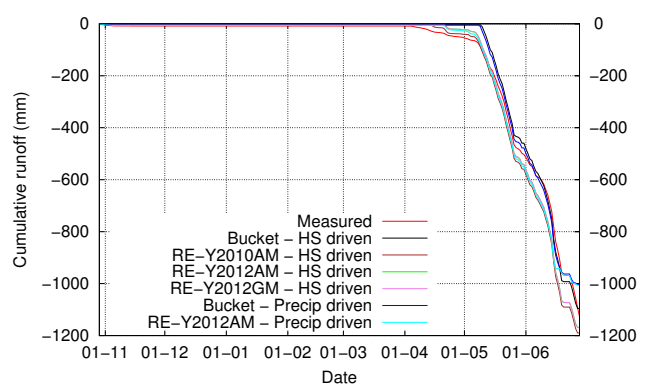

(b) 2008-2009

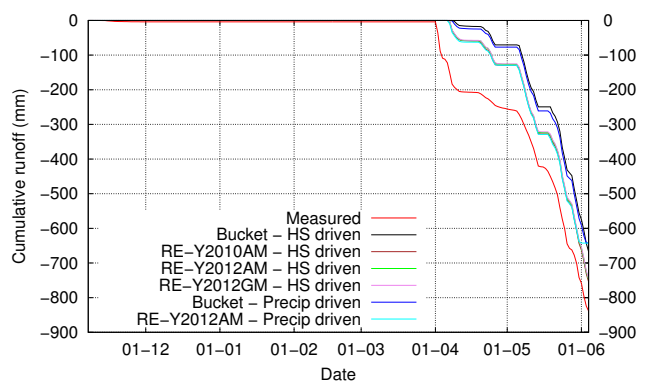

(d) $2010-2011$

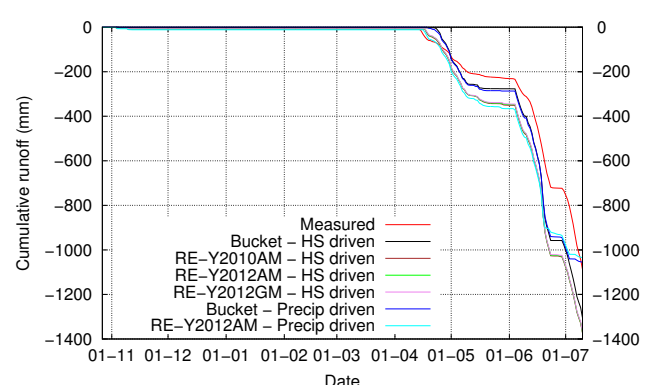

(f) 2012-2013

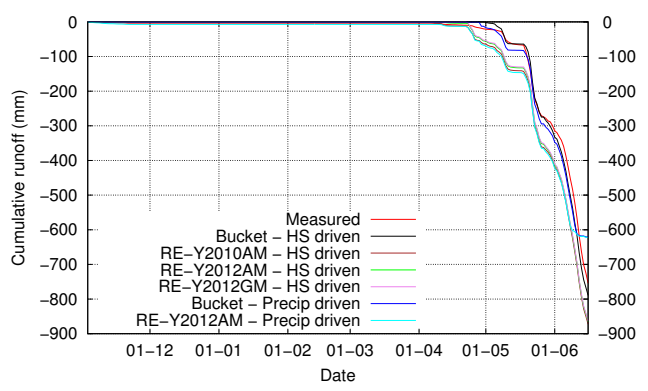

(g) 2013-2014

Figure S7: Cumulative runoff $(\mathrm{mm})$, continued. 


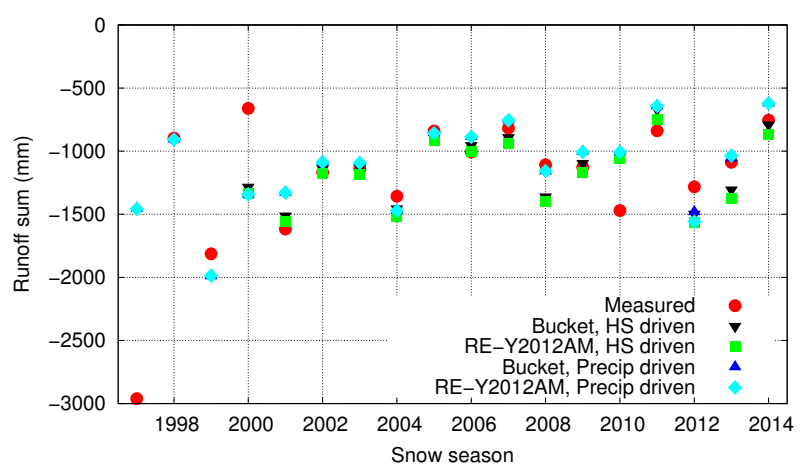

Figure S8: Seasonal runoff sums $(\mathrm{mm})$ from the perspective of the snowpack mass balance (negative values denote snowpack outflow).

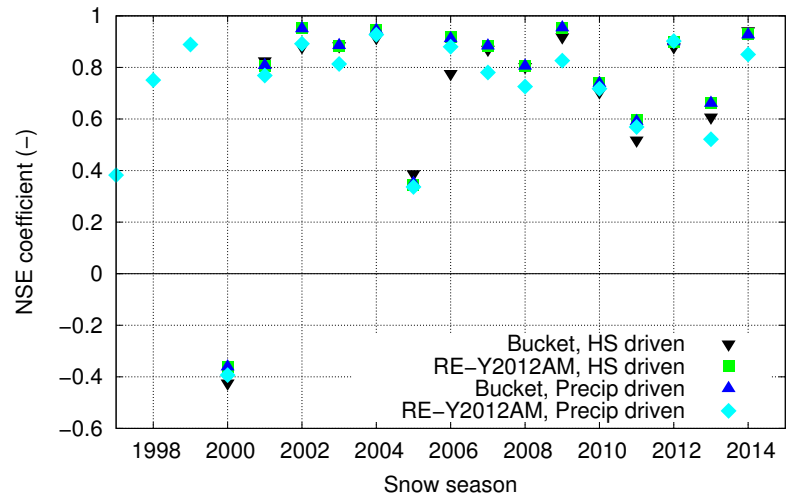

Figure S9: Nash-Sutcliffe model efficiency coefficients for daily runoff sums.

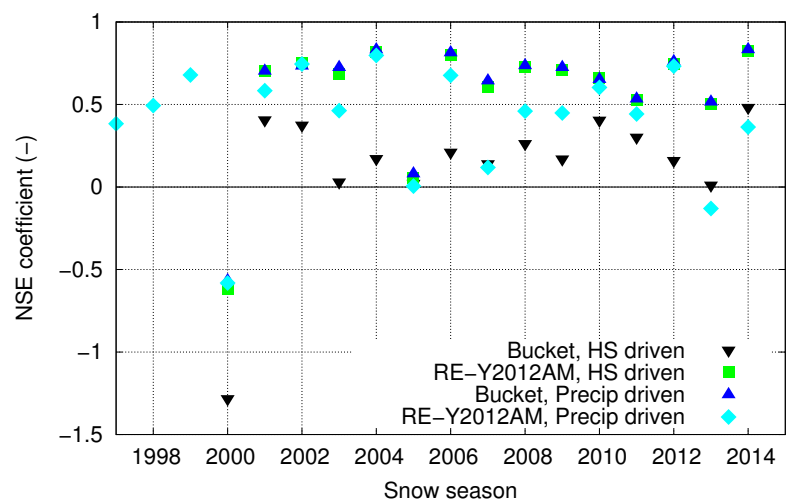

Figure S10: Nash-Sutcliffe model efficiency coefficients for hourly runoff sums. 


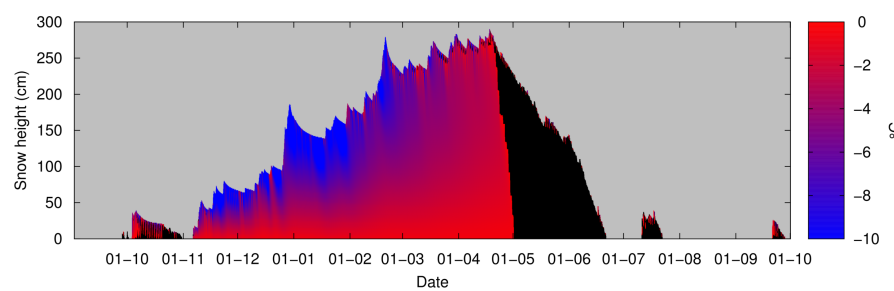

(a) $1999-2000$

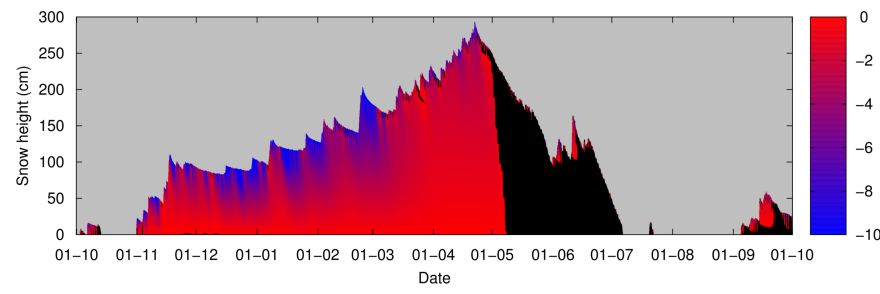

(c) $2000-2001$

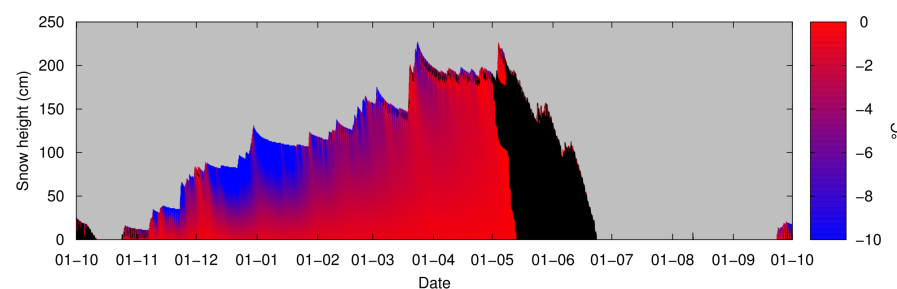

(e) 2001-2002

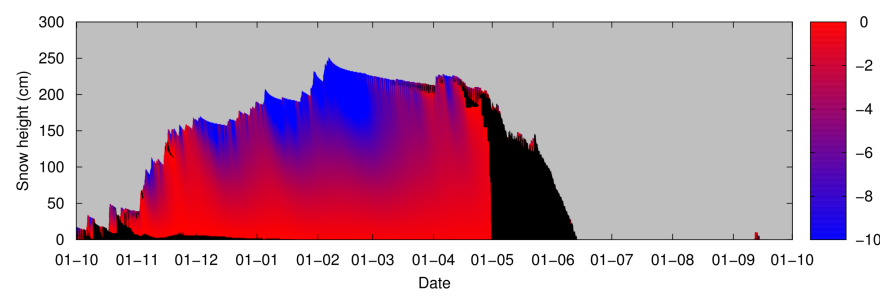

(g) 2002-2003

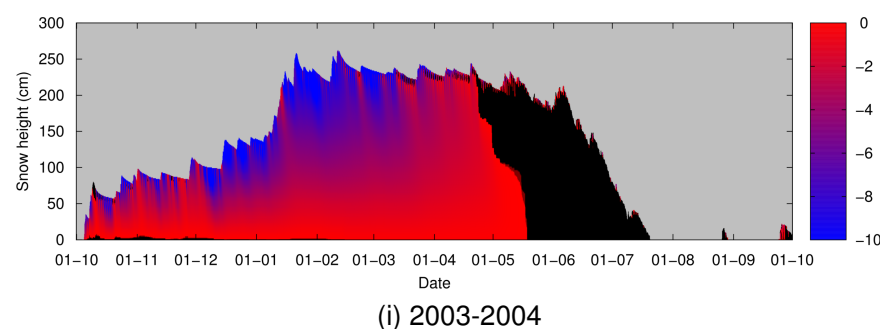

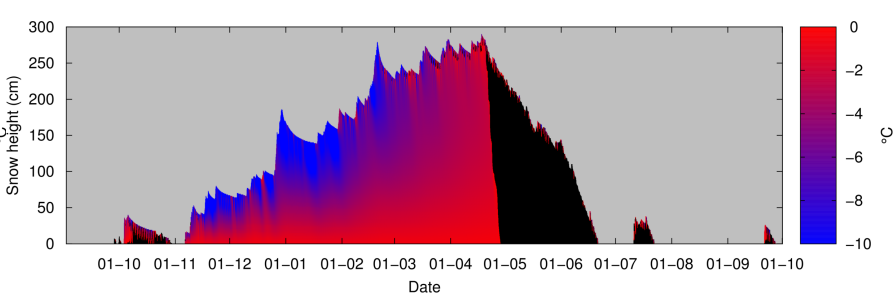

(b) $1999-2000$

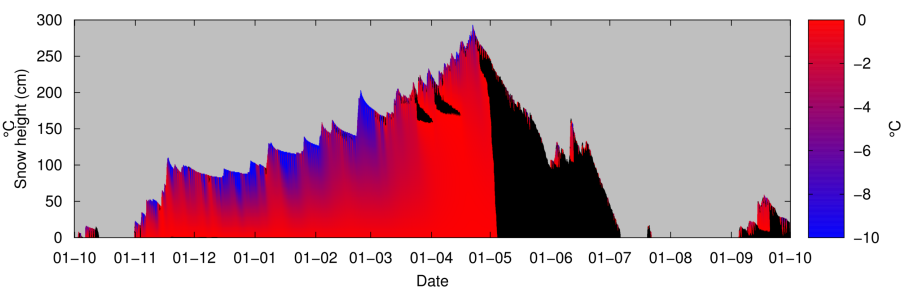

(d) $2000-2001$

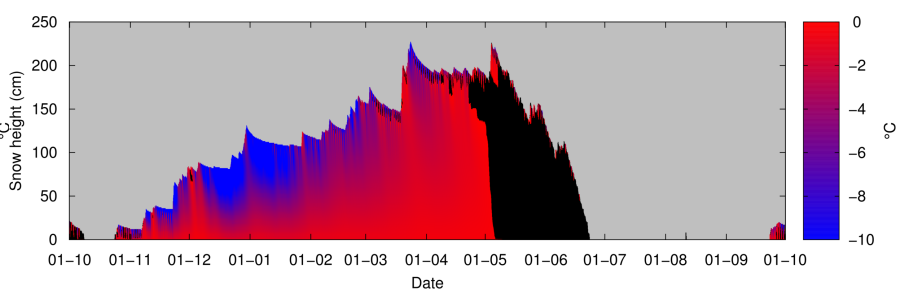

(f) 2001-2002

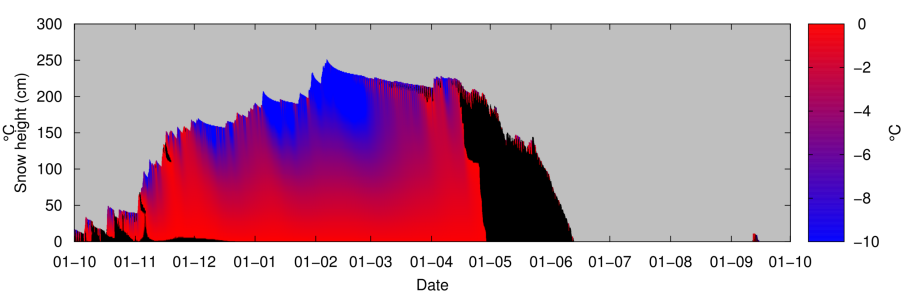

(h) $2002-2003$

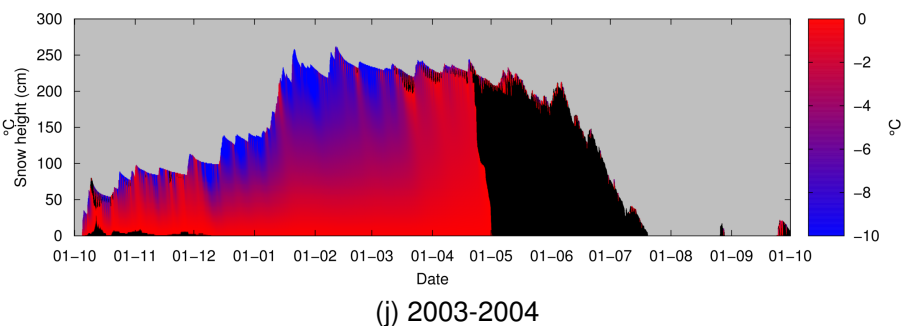

Figure S11: Snow temperature $\left({ }^{\circ} \mathrm{C}\right)$ for the snow height-driven simulations with the bucket scheme (left), and with RE-Y2012AM (right). Snow at exactly $0{ }^{\circ} \mathrm{C}$ coloured black to mark areas of the snowpack that are melting or freezing. 


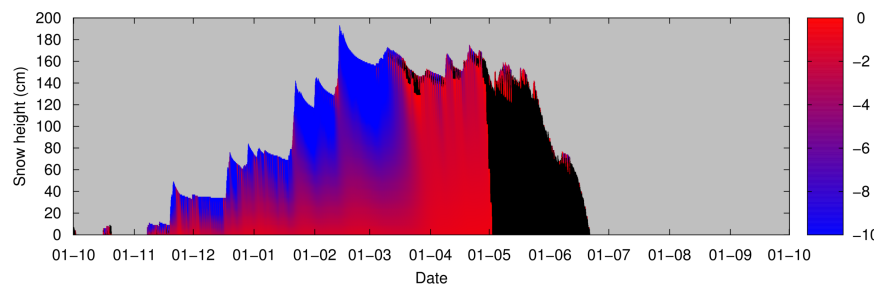

(a) 2004-2005

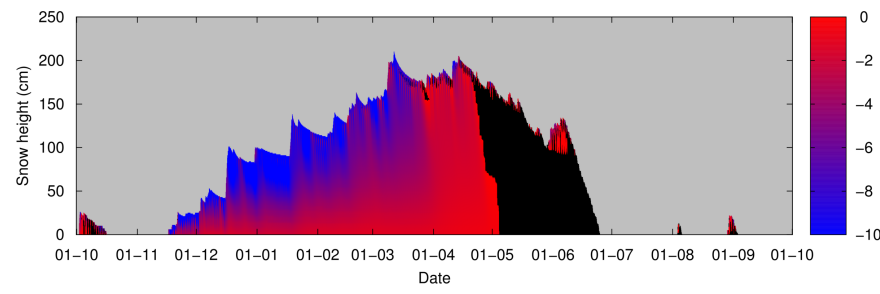

(c) $2005-2006$

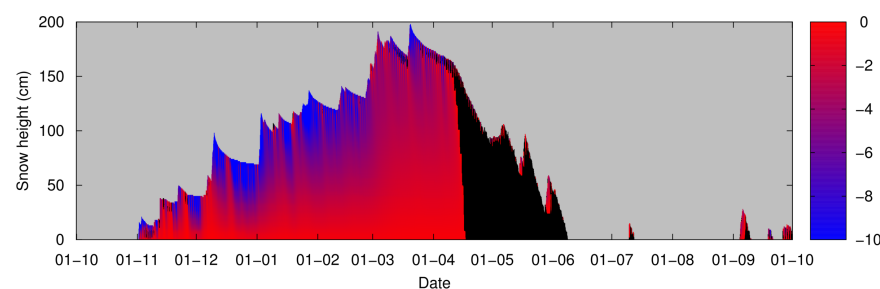

(e) 2006-2007

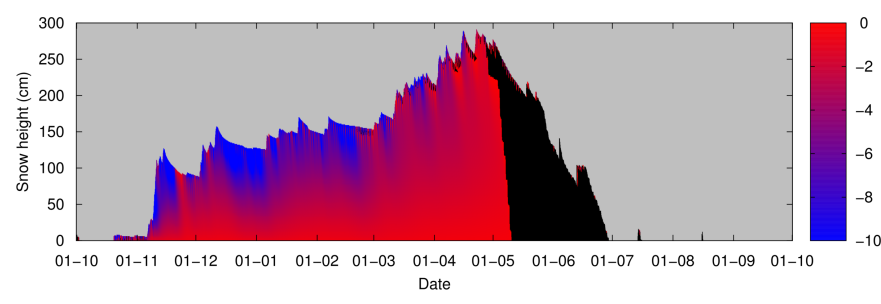

(g) $2007-2008$

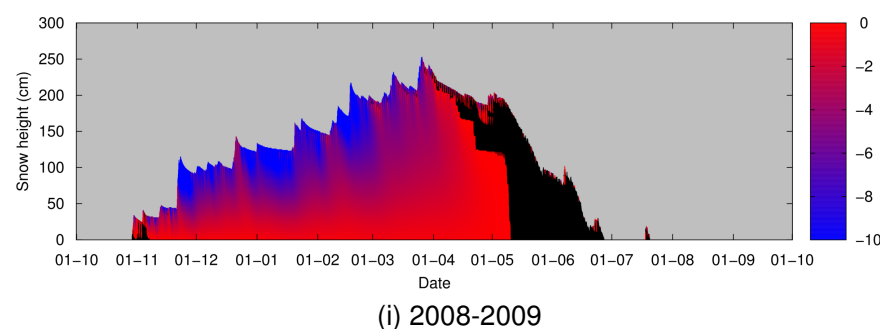

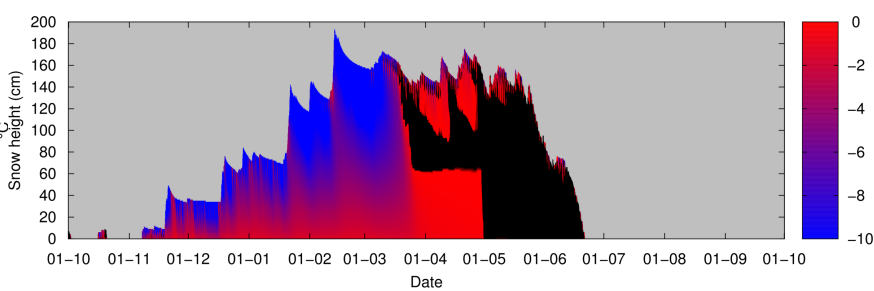

(b) 2004-2005

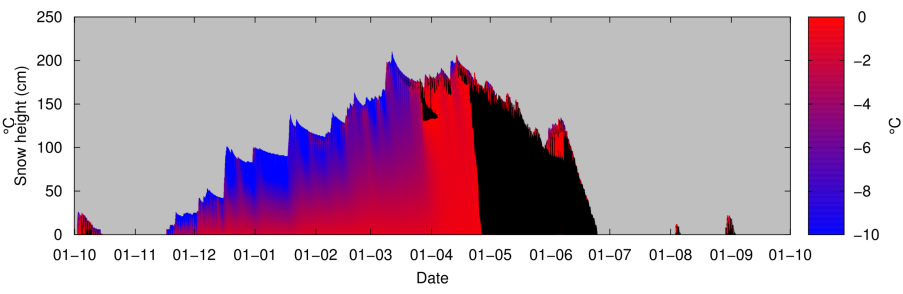

(d) $2005-2006$

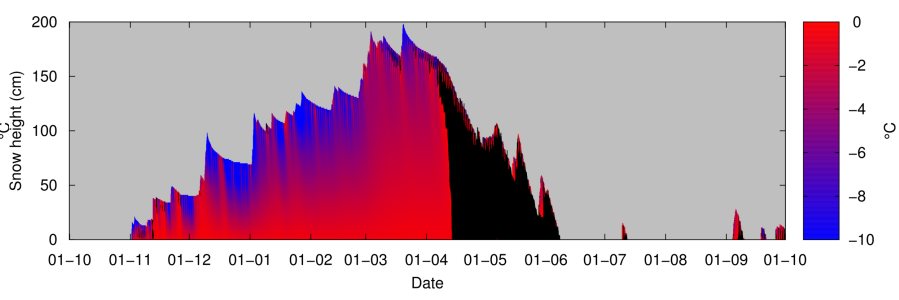

(f) 2006-2007

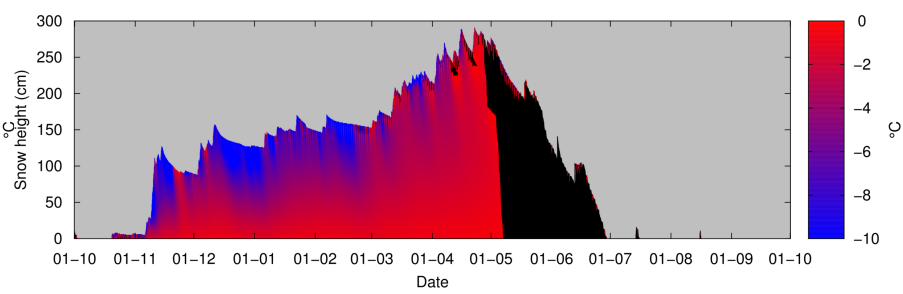

(h) 2007-2008

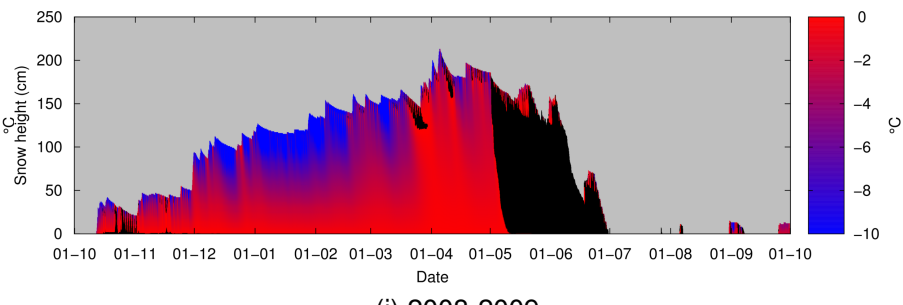

(j) 2008-2009

Figure S12: Snow temperature $\left({ }^{\circ} \mathrm{C}\right)$ for the snow height-driven simulations with the bucket scheme (left), and with RE-Y2012AM (right), continued. Snow at exactly $0{ }^{\circ} \mathrm{C}$ coloured black to mark areas of the snowpack that are melting or freezing. 


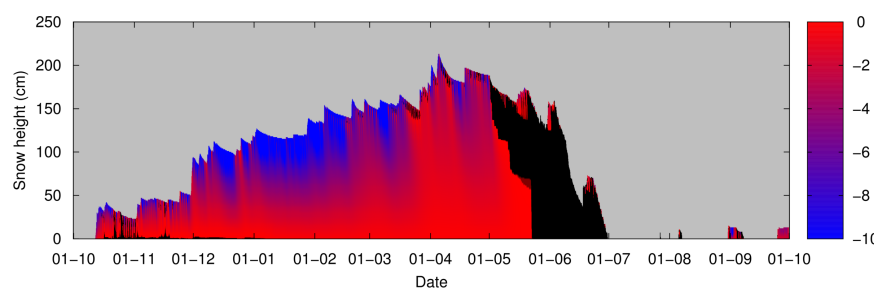

(a) $2009-2010$

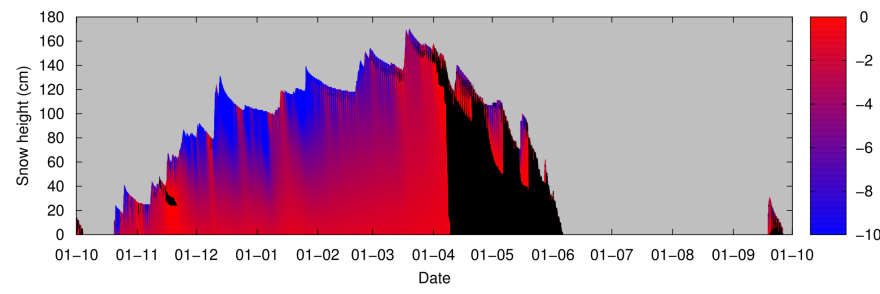

(c) $2010-2011$

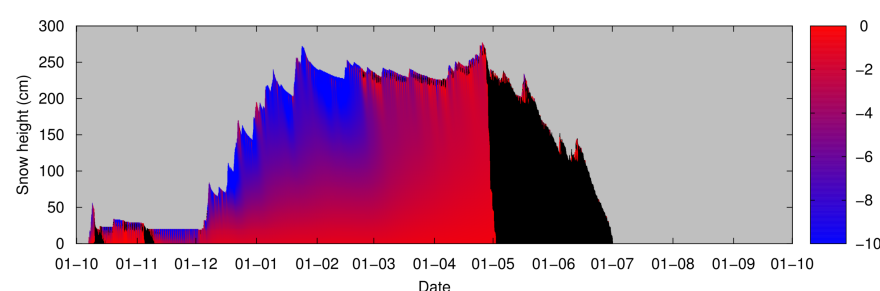

(e) 2011-2012

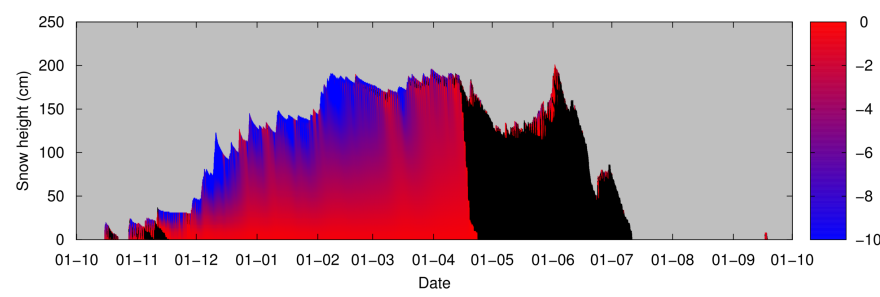

(g) $2012-2013$

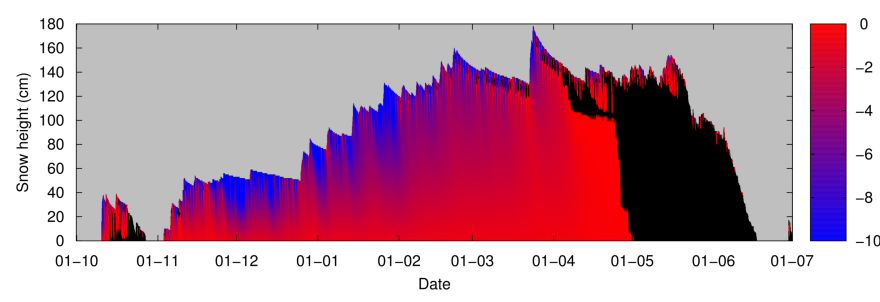

(i) 2013-2014

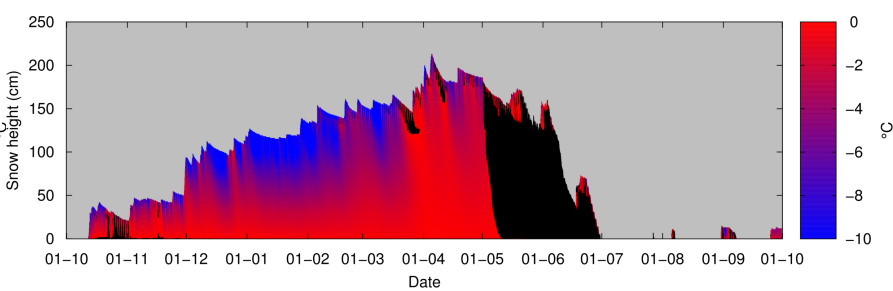

(b) $2009-2010$

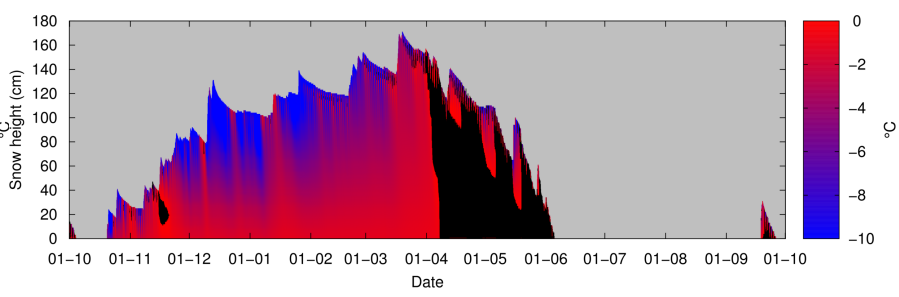

(d) $2010-2011$

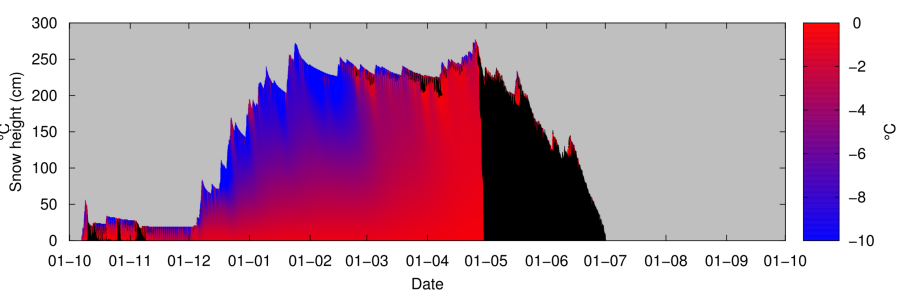

(f) 2011-2012

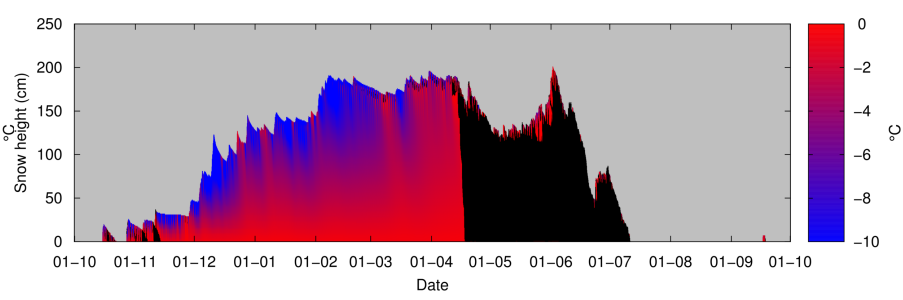

(h) 2012-2013

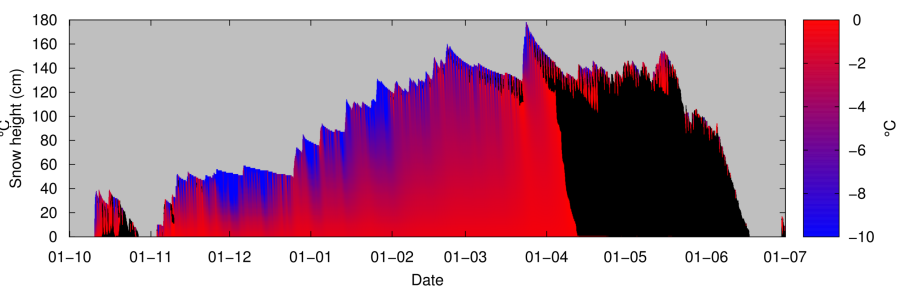

(j) 2013-2014

Figure S13: Snow temperature $\left({ }^{\circ} \mathrm{C}\right)$ for the snow height-driven simulations with the bucket scheme (left), and with RE-Y2012AM (right), continued. Snow at exactly $0{ }^{\circ} \mathrm{C}$ coloured black to mark areas of the snowpack that are melting or freezing. 


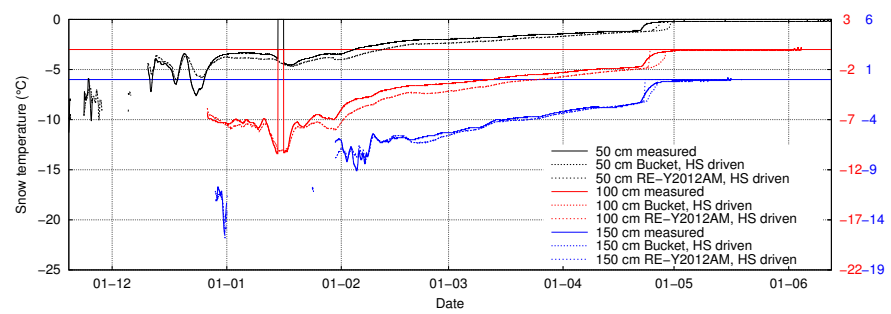

(a) $1999-2000$

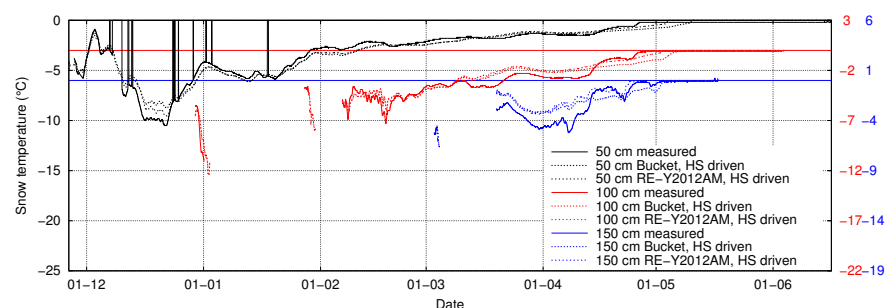

(c) 2001-2002

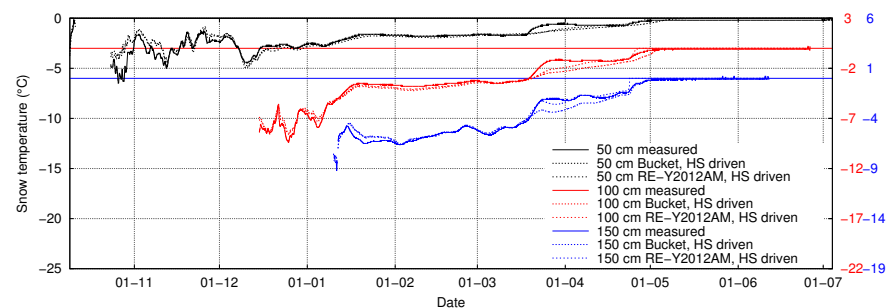

(e) 2003-2004

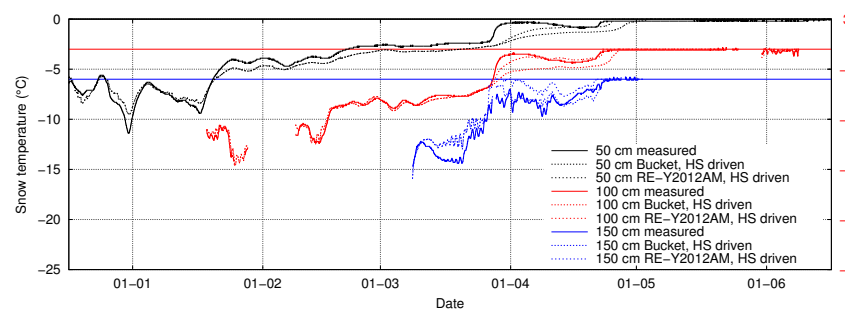

(g) $2005-2006$

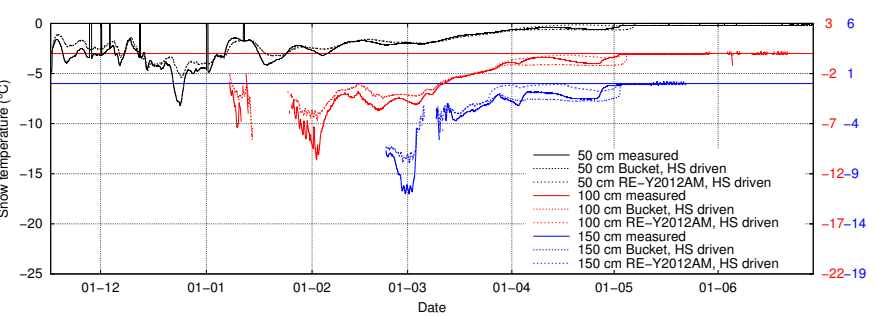

(b) $2000-2001$

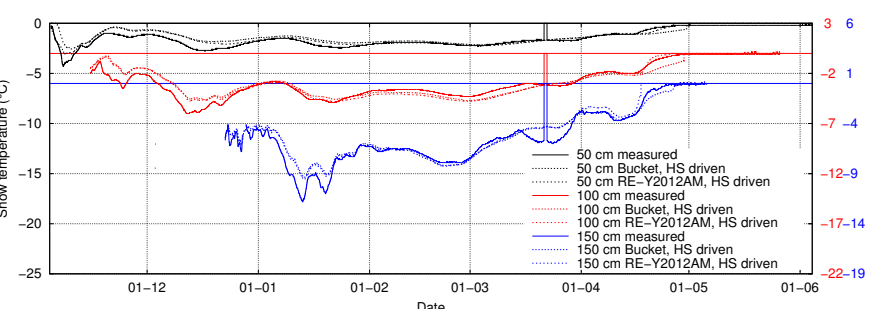

(d) $2002-2003$

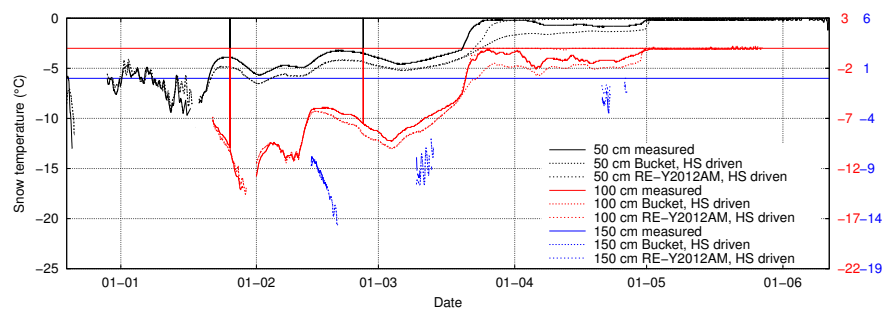

(f) 2004-2005

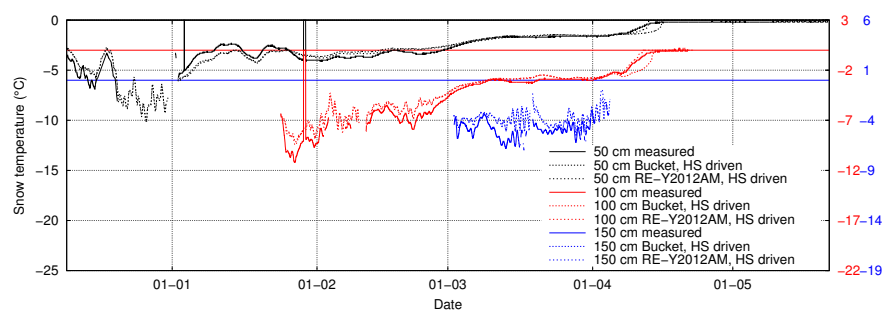

(h) 2006-2007

Figure S14: Measured and modelled snow temperatures at 50,100 and $150 \mathrm{~cm}$ above the surface. Values are only plotted when the snow height was at least $20 \mathrm{~cm}$ more than the height of the temperature sensor. 


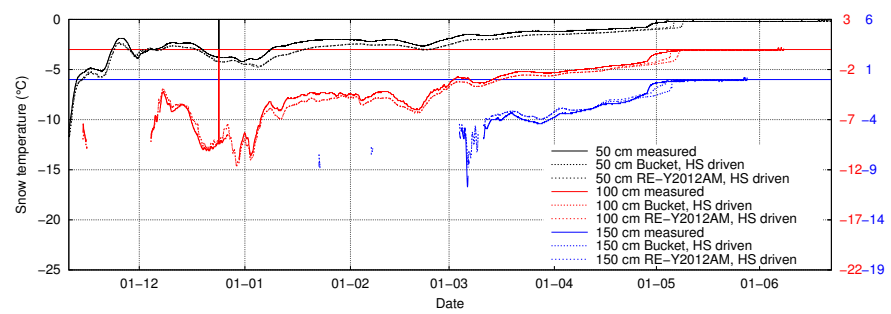

(a) $2007-2008$

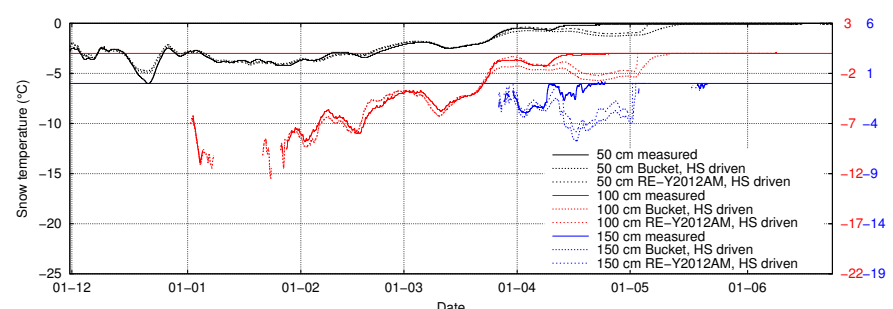

(c) $2009-2010$

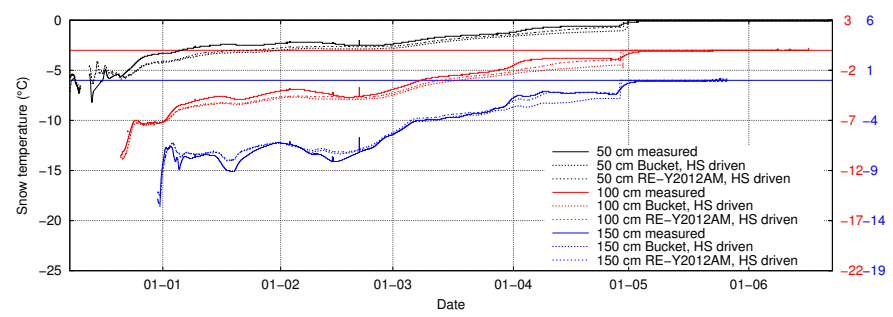

(e) $2011-2012$

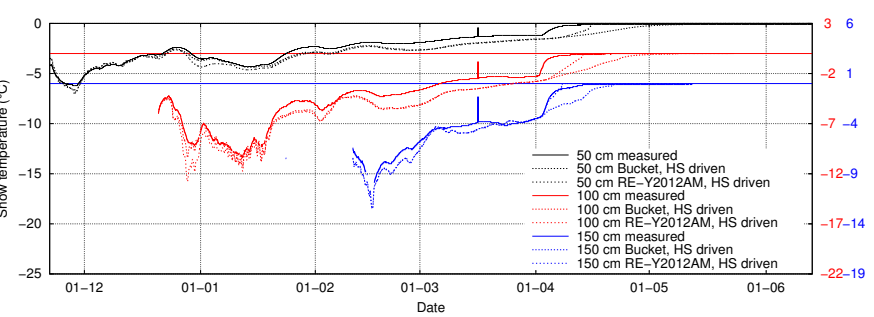

(b) 2008-2009

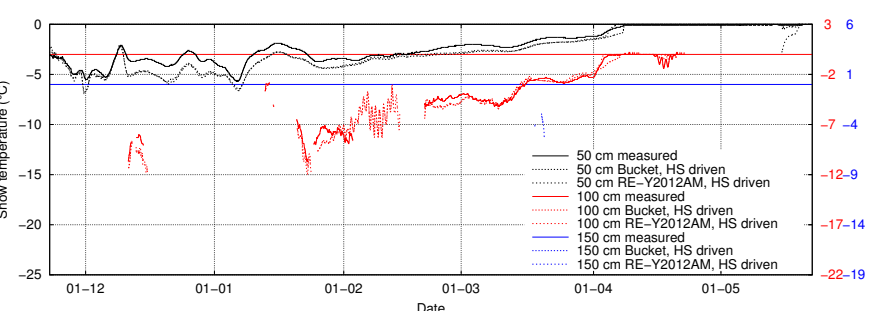

(d) $2010-2011$

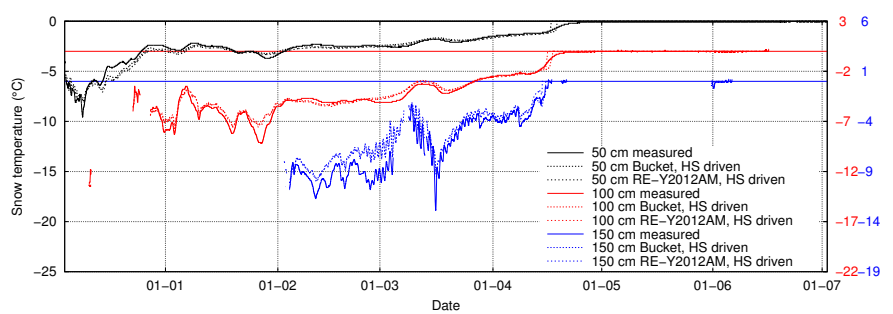

(f) $2012-2013$

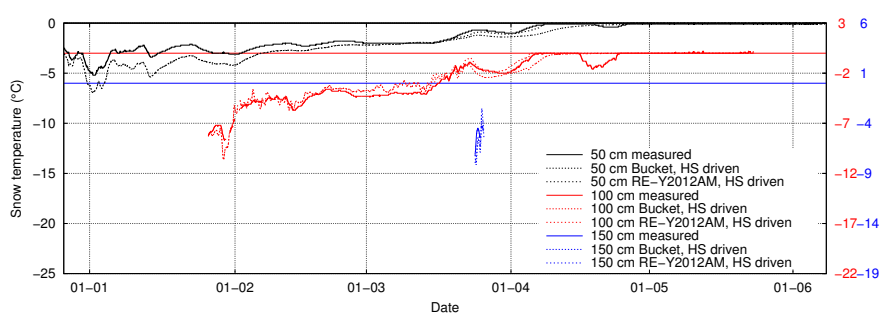

(g) 2013-2014

Figure S15: Measured and modelled snow temperatures at 50,100 and $150 \mathrm{~cm}$ above the surface, continued. Values are only plotted when the snow height was at least $20 \mathrm{~cm}$ more than the height of the temperature sensor. 


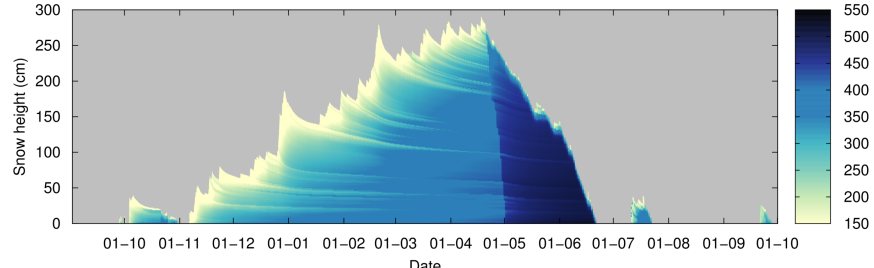

(a) $1999-2000$

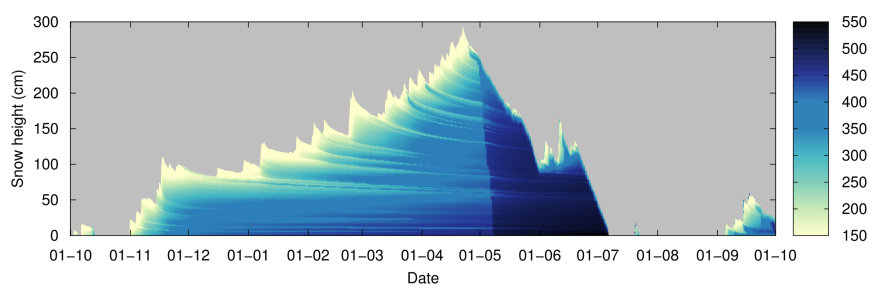

(c) $2000-2001$

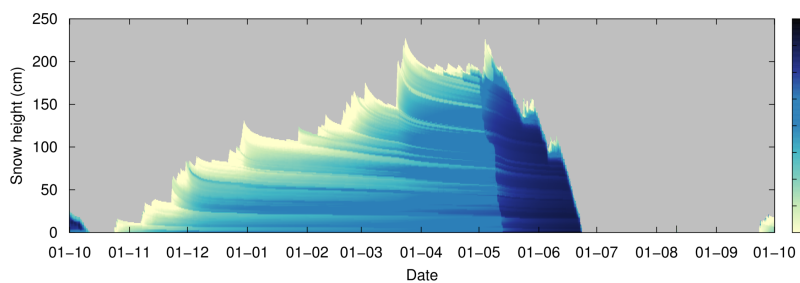

(e) 2001-2002

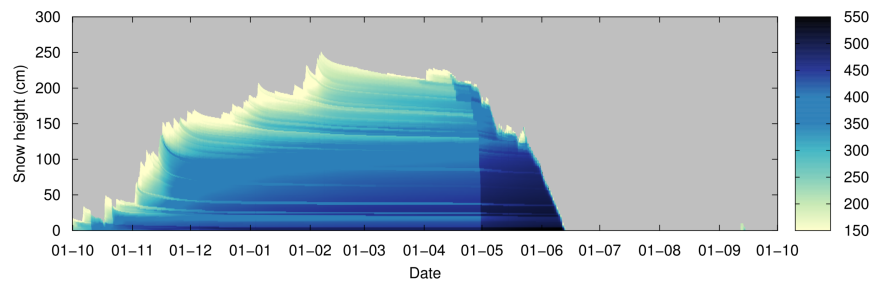

(g) 2002-2003

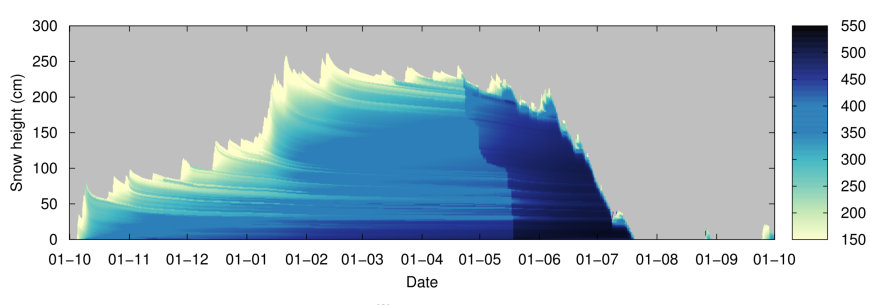

(i) $2003-2004$

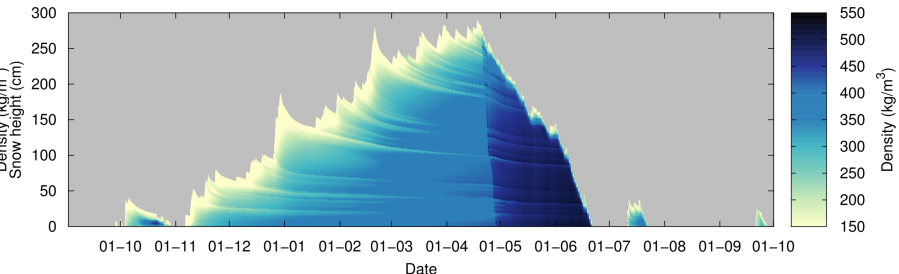

(b) $1999-2000$

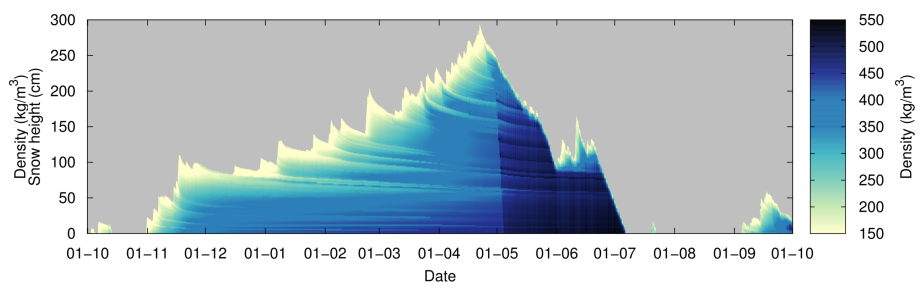

(d) $2000-2001$

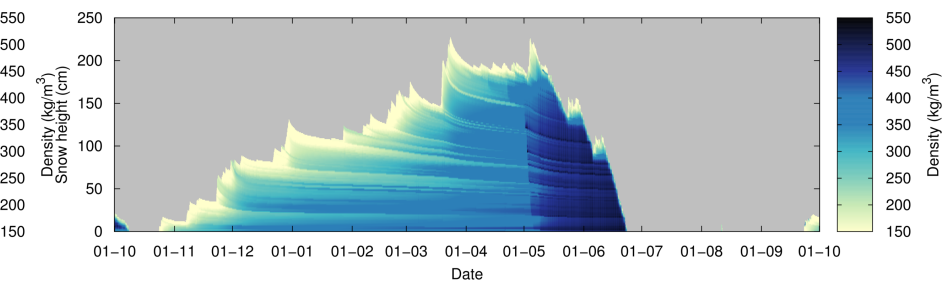

(f) 2001-2002

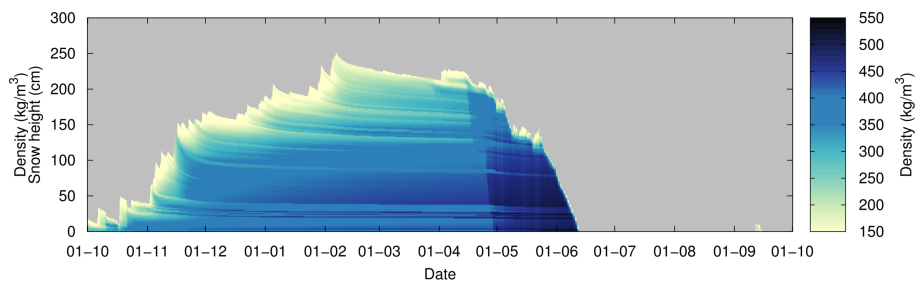

(h) 2002-2003

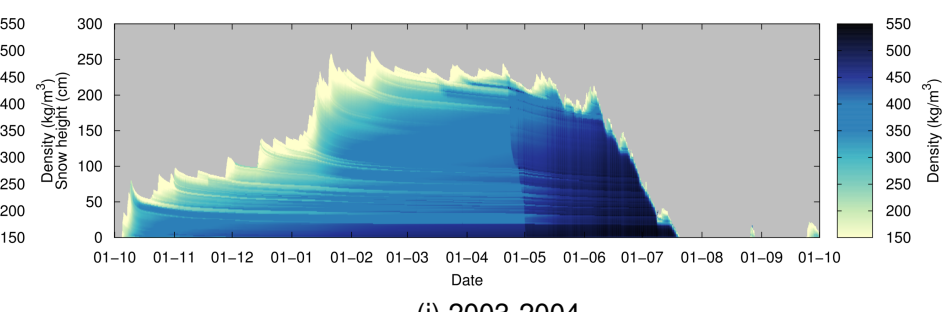

(j) 2003-2004

Figure S16: Snow density $\left(\mathrm{kg} \mathrm{m}^{-3}\right)$ for the snow height-driven simulations with the bucket scheme (left), and with RE-Y2012AM (right). 


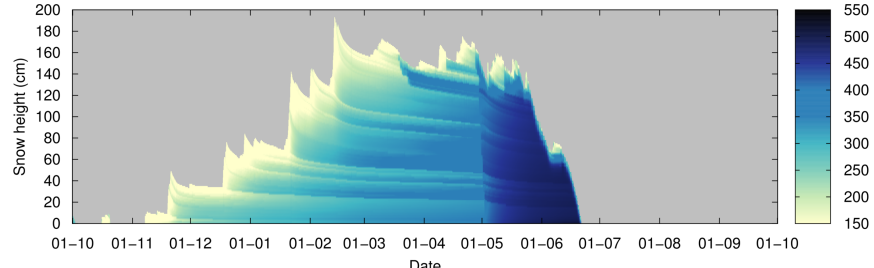

(a) 2004-2005

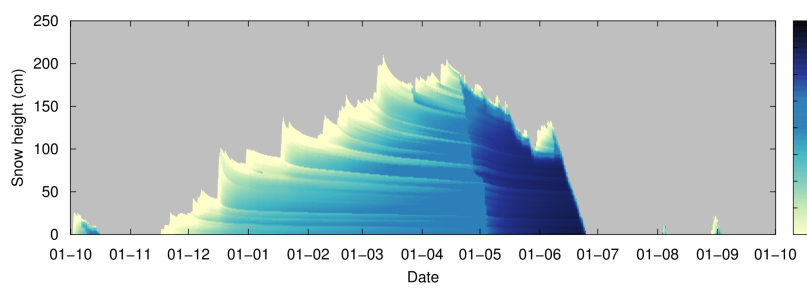

(c) $2005-2006$

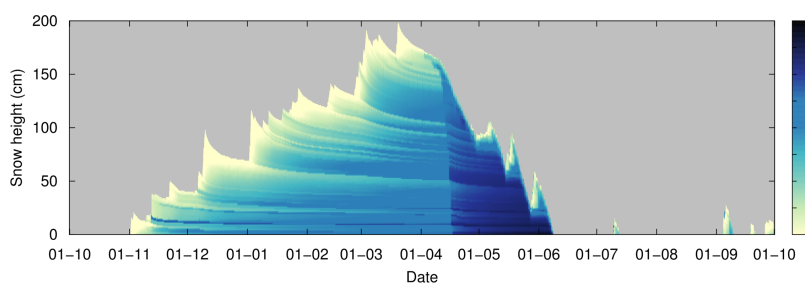

(e) 2006-2007

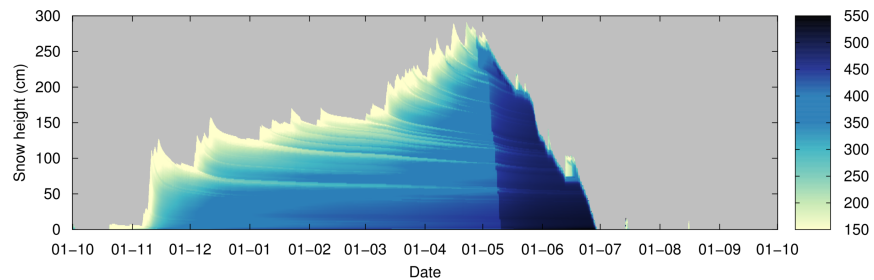

(g) $2007-2008$

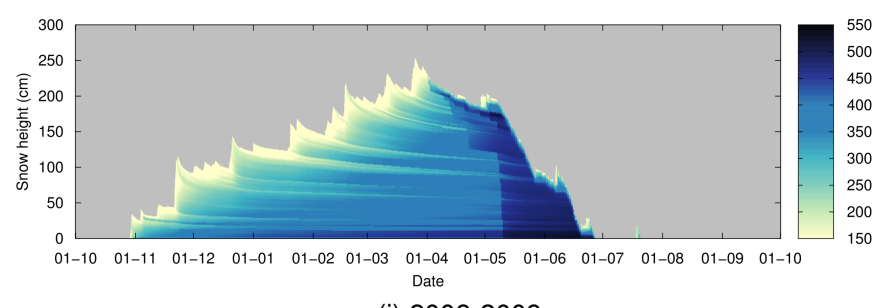

(i) 2008-2009

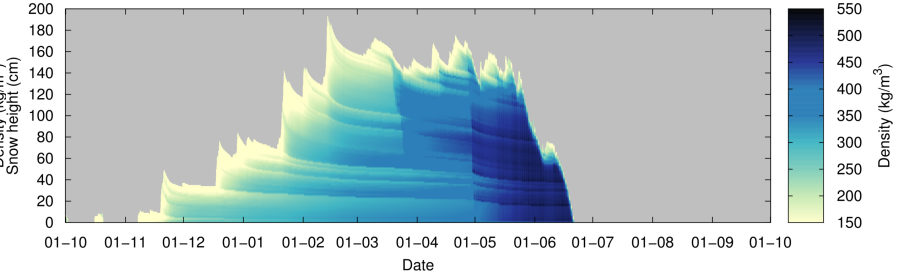

(b) 2004-2005

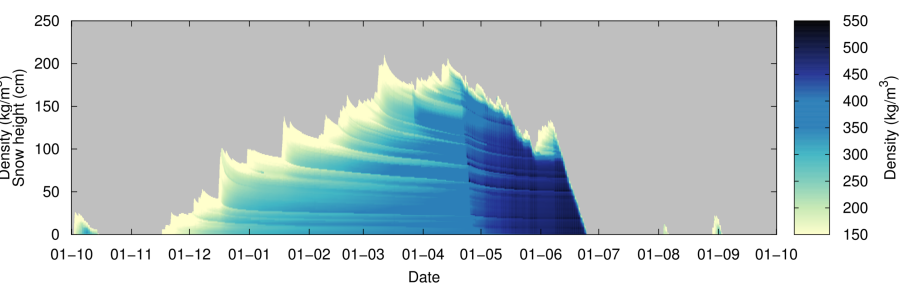

(d) $2005-2006$

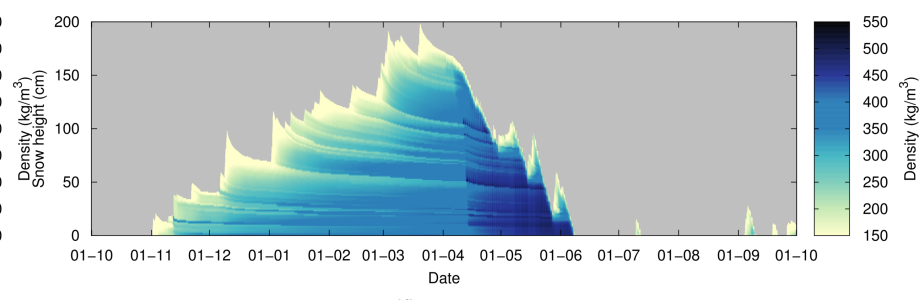

(f) 2006-2007

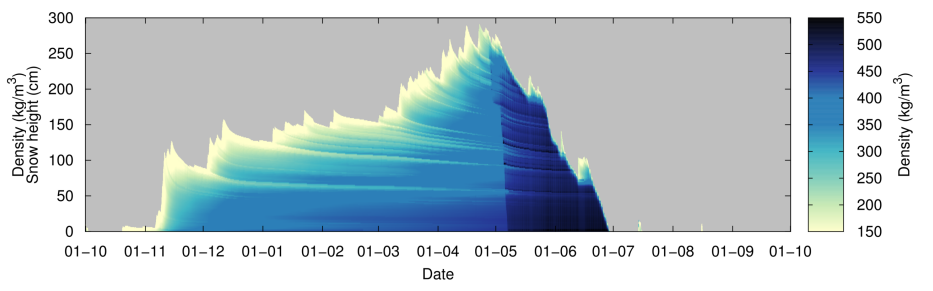

(h) $2007-2008$

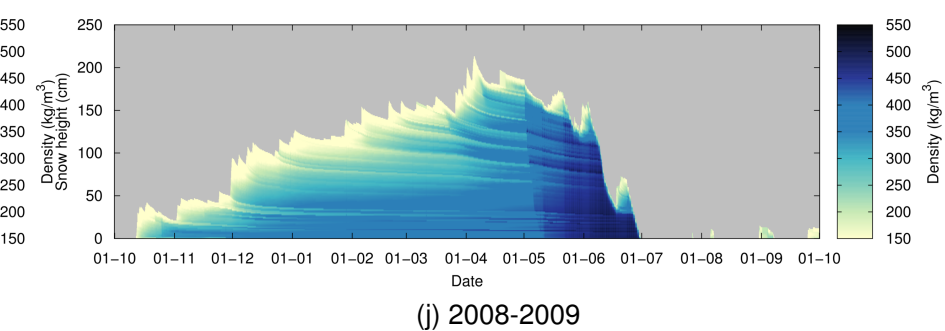

(j) 2008-2009

Figure S17: Snow density $\left(\mathrm{kg} \mathrm{m}^{-3}\right)$ for the snow height-driven simulations with the bucket scheme (left), and with RE-Y2012AM (right), continued. 


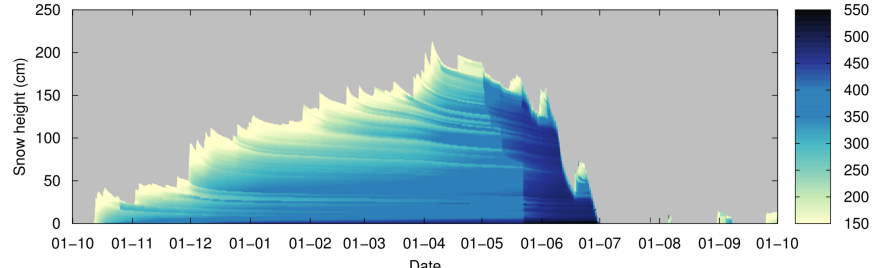

(a) $2009-2010$

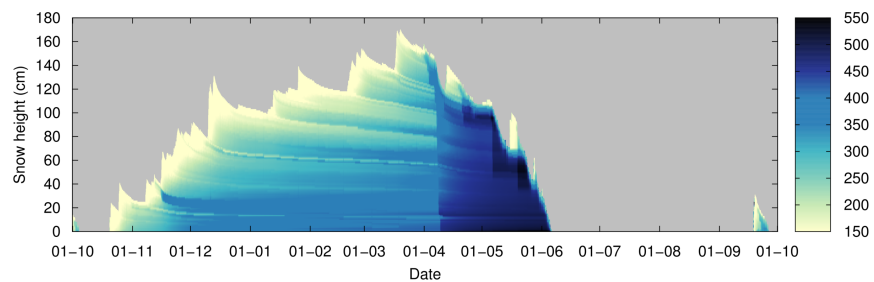

(c) $2010-2011$

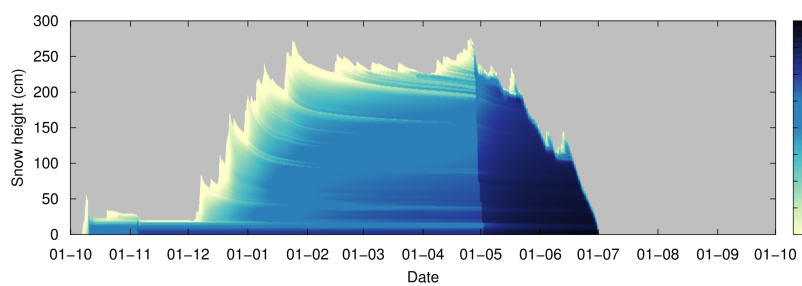

(e) 2011-2012

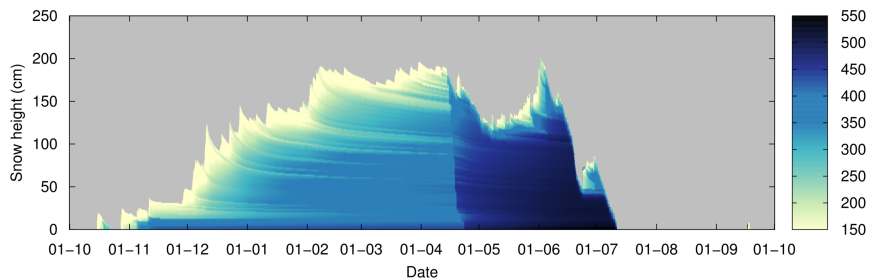

(g) $2012-2013$

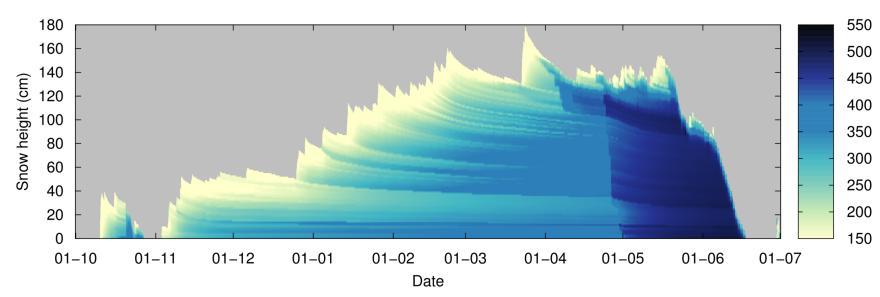

(i) 2013-2014

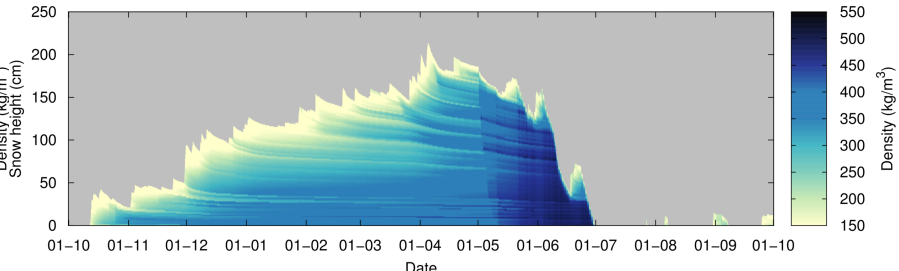

(b) $2009-2010$

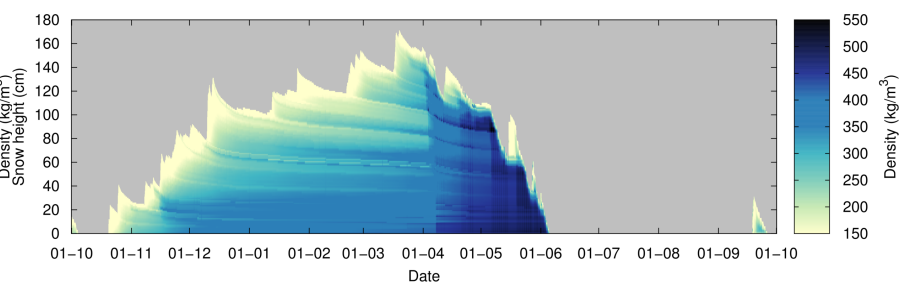

(d) $2010-2011$

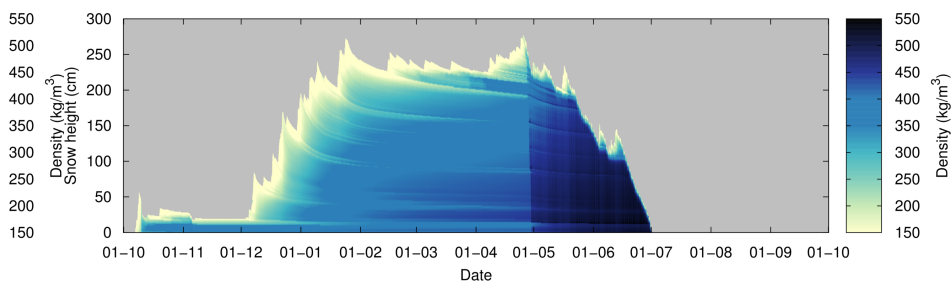

(f) $2011-2012$

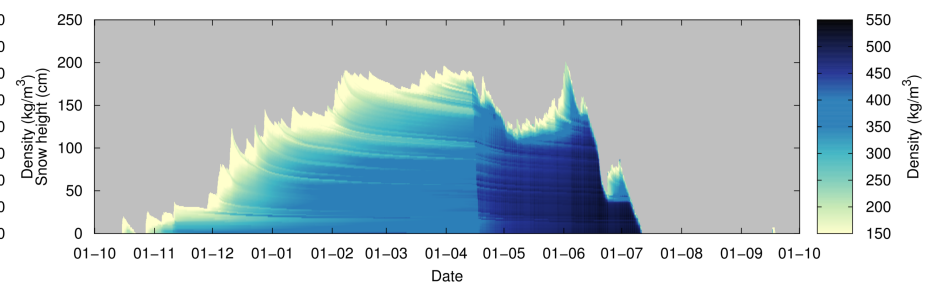

(h) $2012-2013$

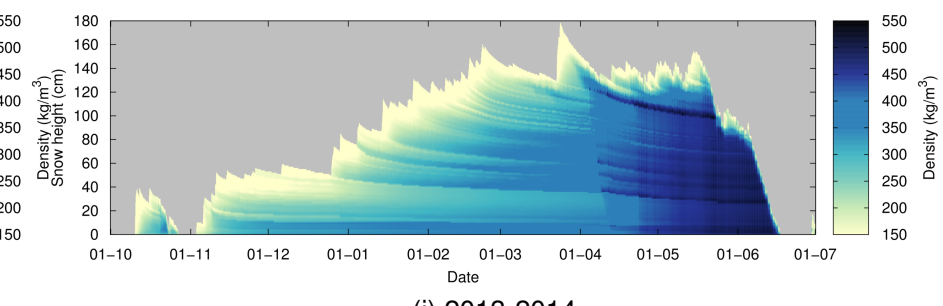

(j) 2013-2014

Figure S18: Snow density $\left(\mathrm{kg} \mathrm{m}^{-3}\right)$ for the snow height-driven simulations with the bucket scheme (left), and with RE-Y2012AM (right), continued. 


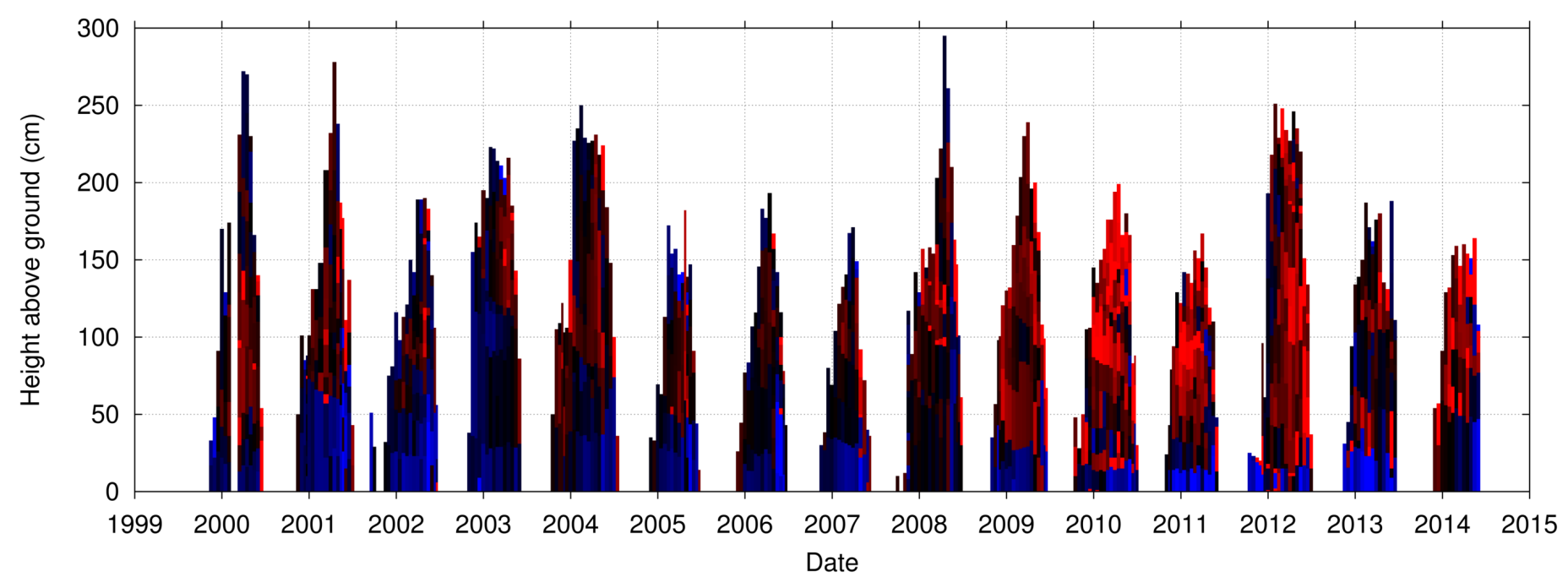

(a)

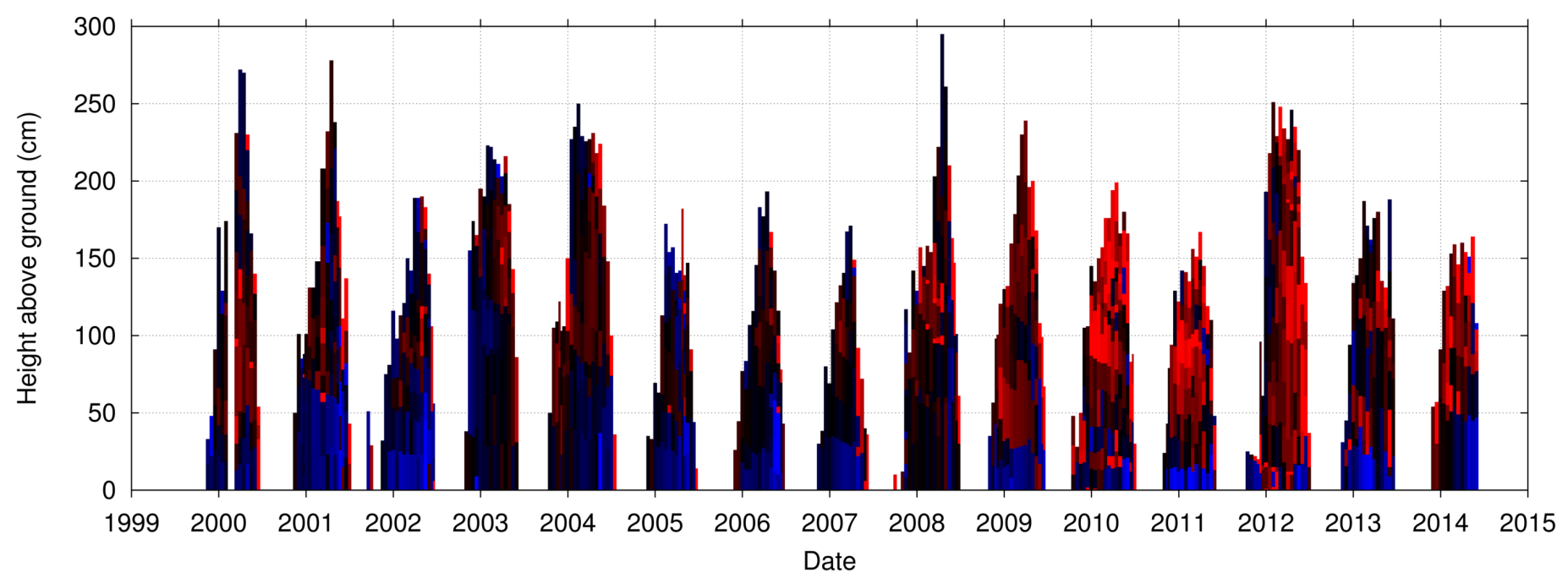

(b)

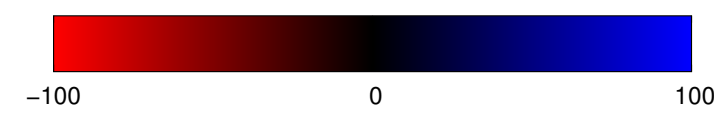

Figure S19: Difference between modelled and measured density $\left(\mathrm{kg} \mathrm{m}^{-3}\right)$ for snow height driven simulations with the bucket scheme (a) and RE-Y2012AM (b). 


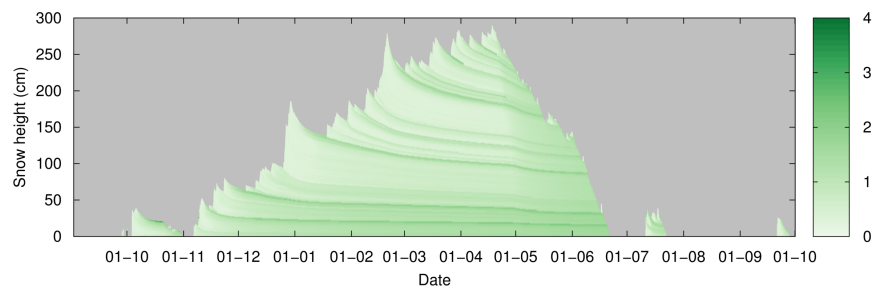

(a) $1999-2000$

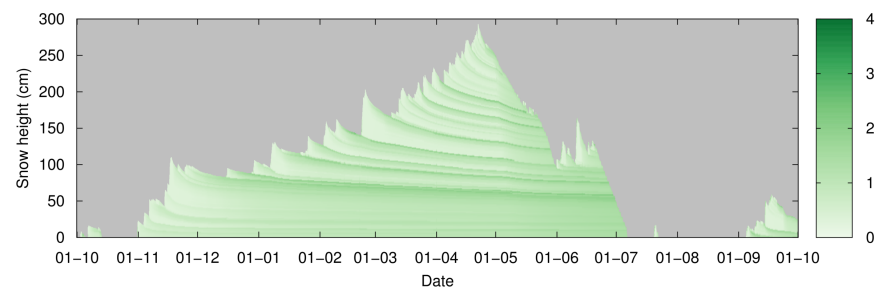

(c) $2000-2001$

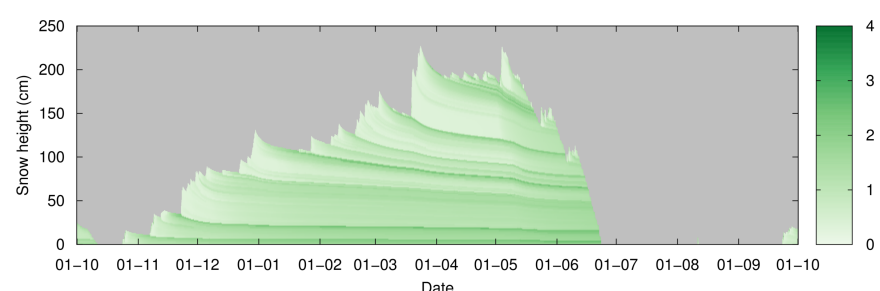

(e) 2001-2002

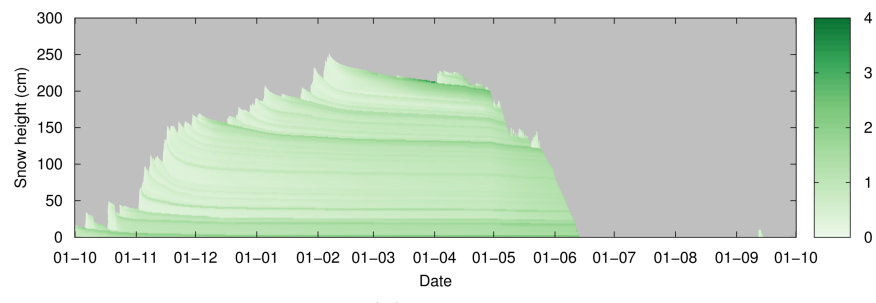

(g) 2002-2003

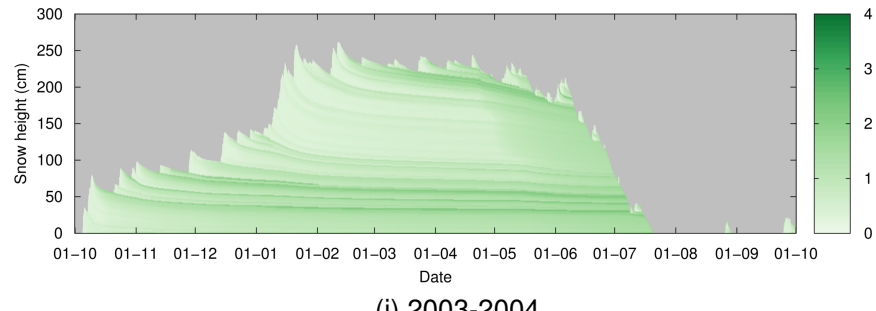

(i) 2003-2004

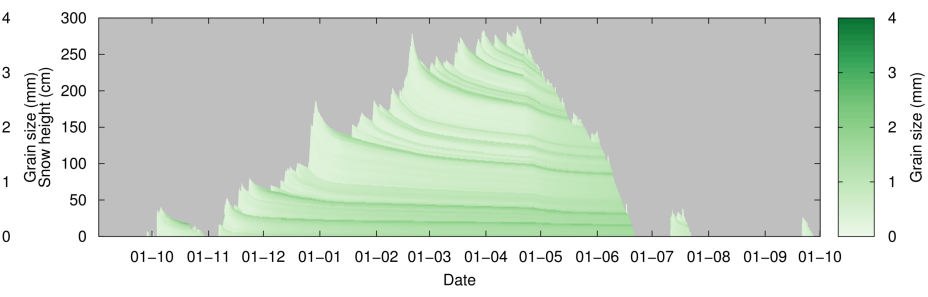

(b) $1999-2000$

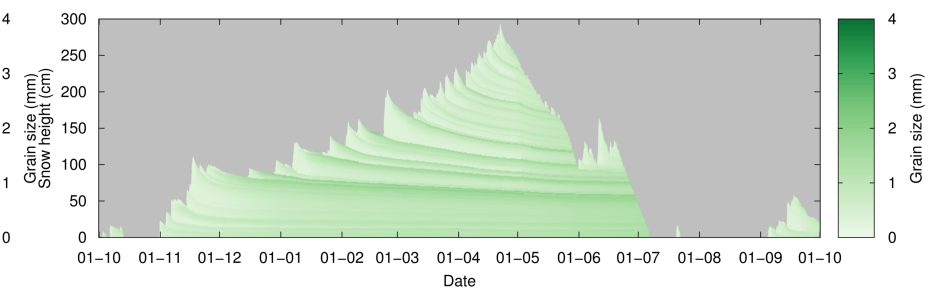

(d) $2000-2001$

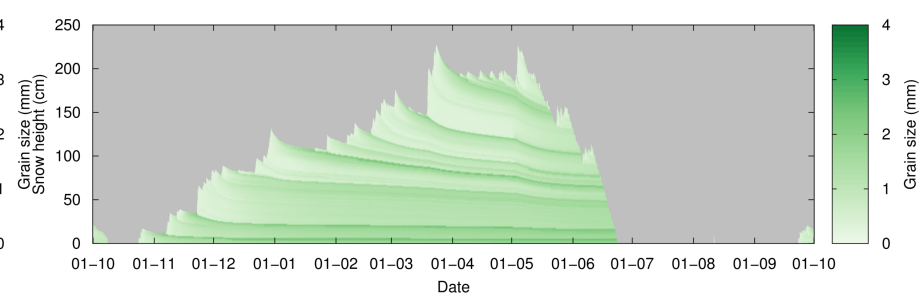

(f) 2001-2002

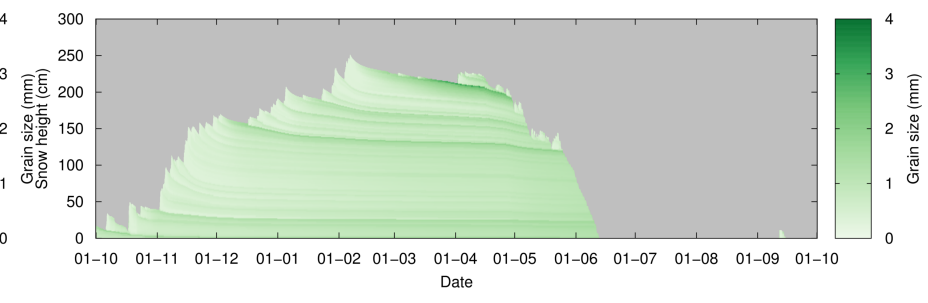

(h) $2002-2003$

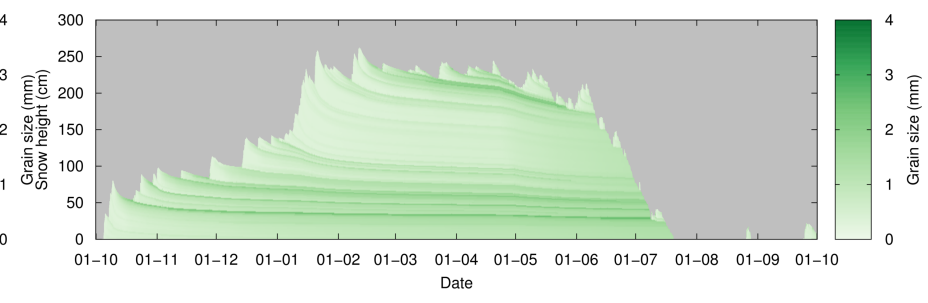

(j) 2003-2004

Figure S20: Grain size $(\mathrm{mm})$ for the snow height-driven simulations with the bucket scheme (left), and with RE-Y2012AM (right). 


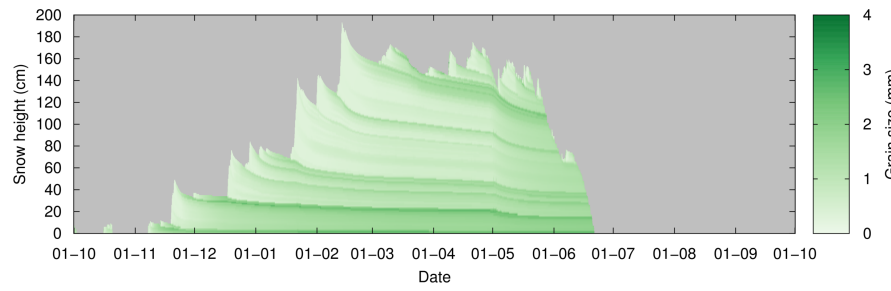

(a) 2004-2005

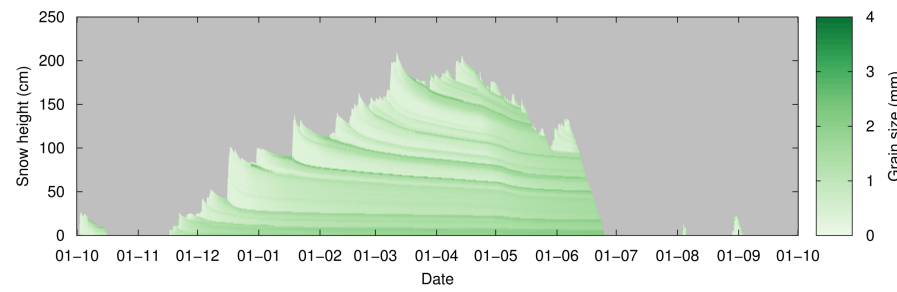

(c) $2005-2006$

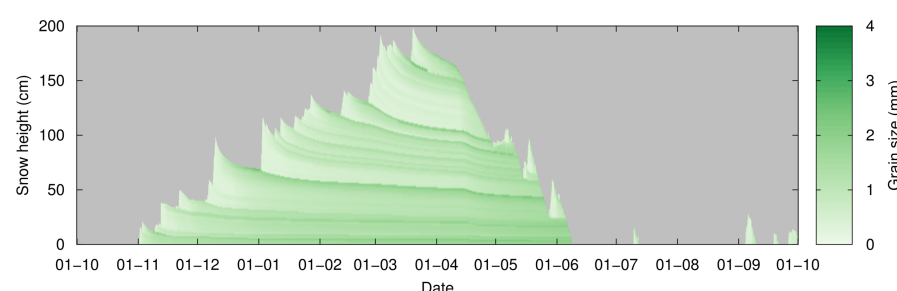

(e) 2006-2007

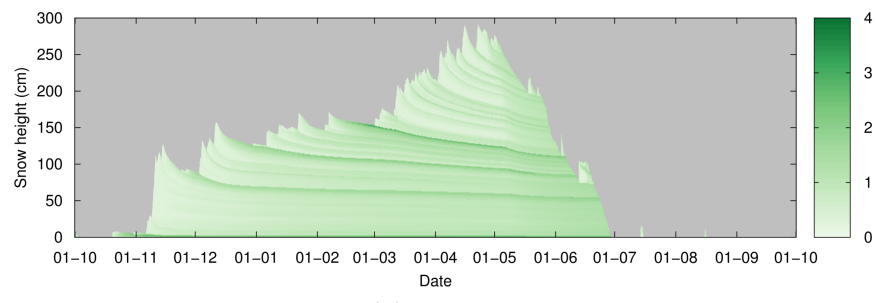

(g) 2007-2008

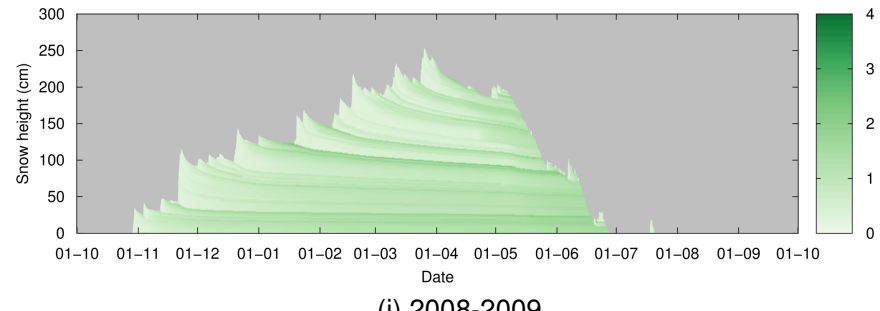

(i) 2008-2009

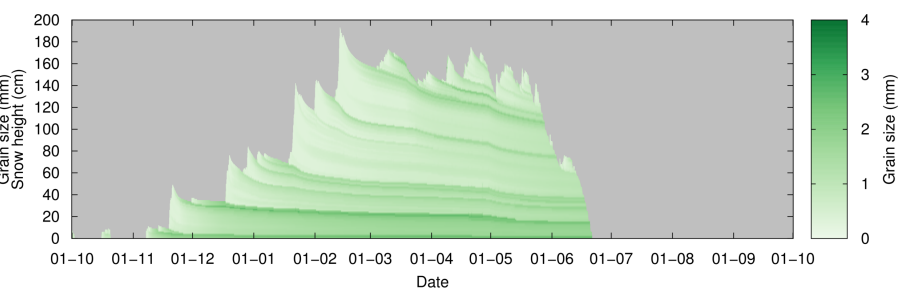

(b) 2004-2005

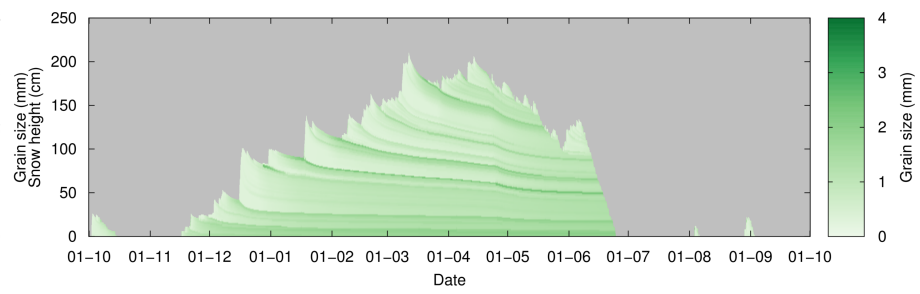

(d) $2005-2006$

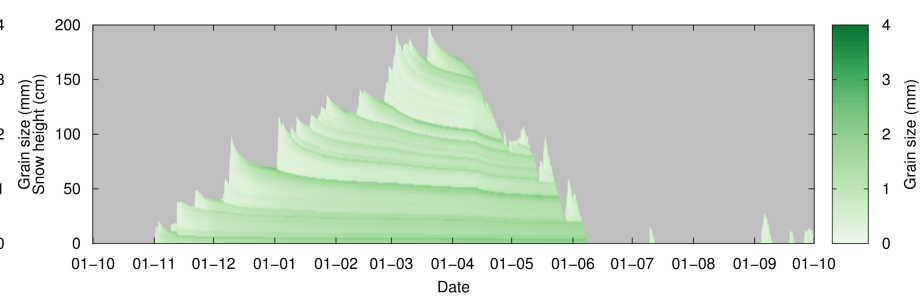

(f) 2006-2007

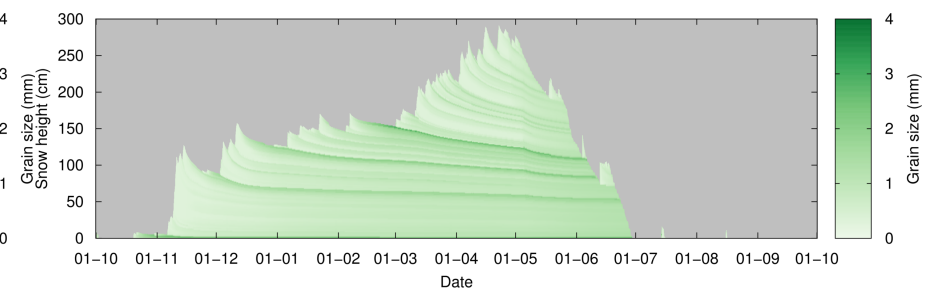

(h) $2007-2008$

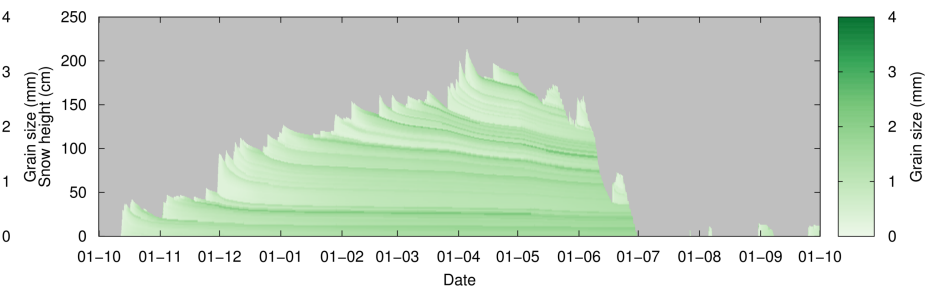

(j) 2008-2009

Figure S21: Grain size $(\mathrm{mm})$ for the snow height-driven simulations with the bucket scheme (left), and with RE-Y2012AM (right), continued. 


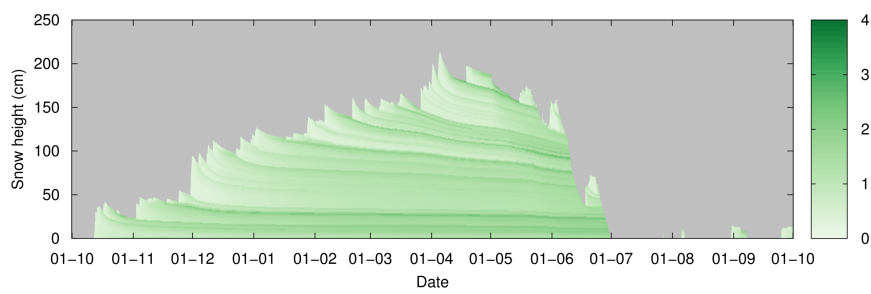

(a) $2009-2010$

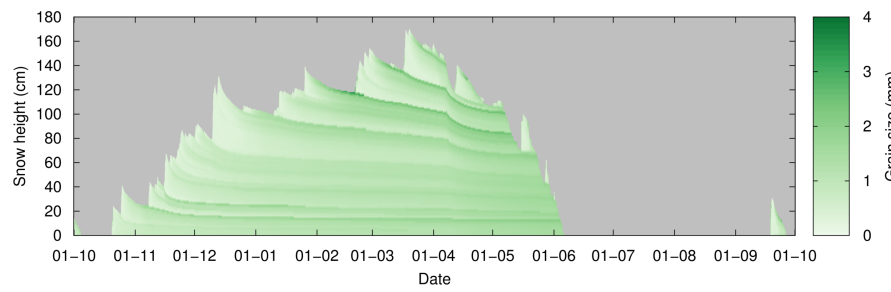

(c) $2010-2011$

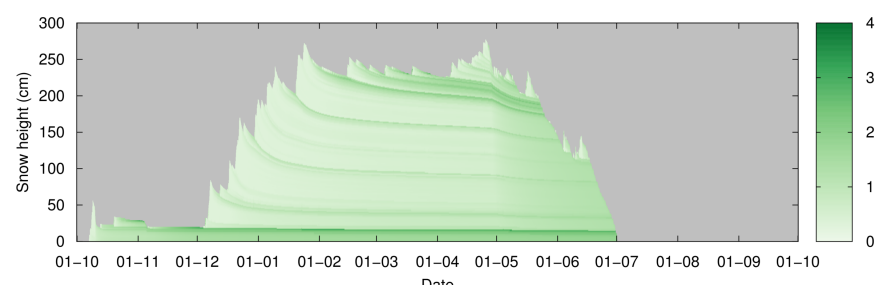

(e) $2011-2012$

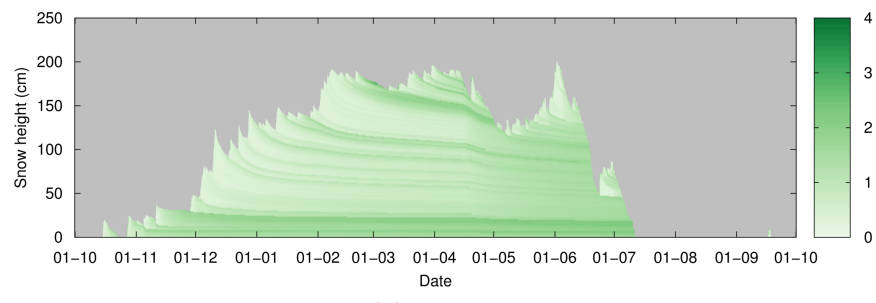

(g) $2012-2013$

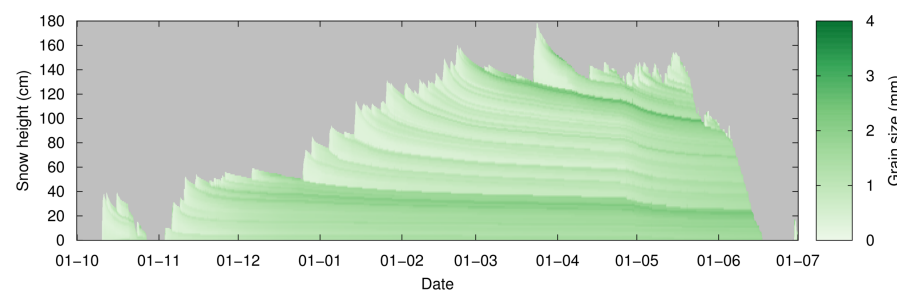

(i) 2013-2014

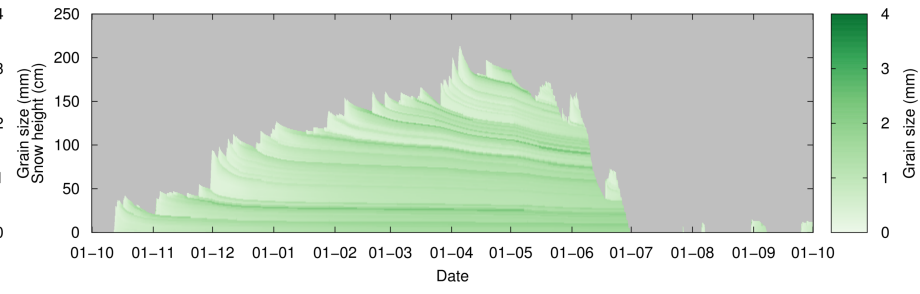

(b) $2009-2010$

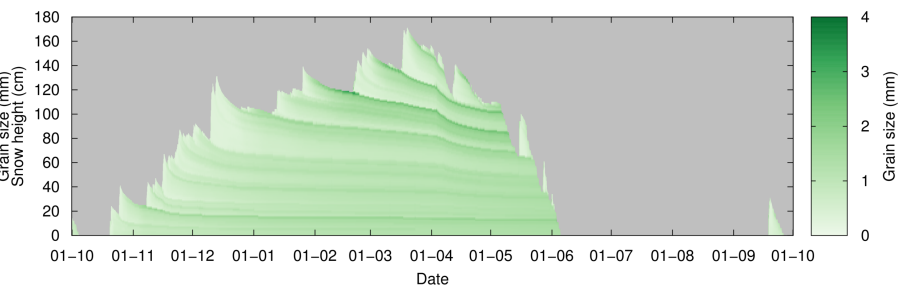

(d) $2010-2011$

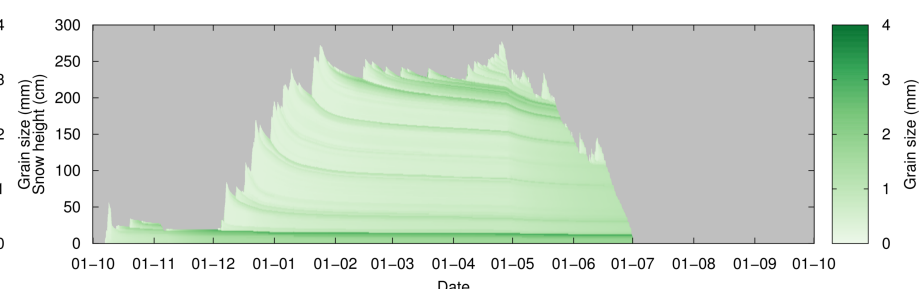

(f) 2011-2012

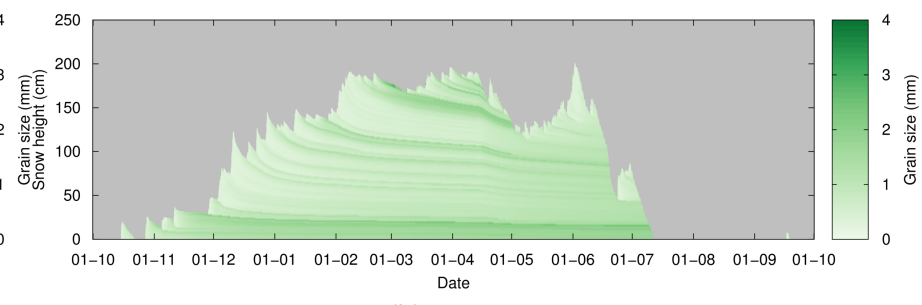

(h) $2012-2013$

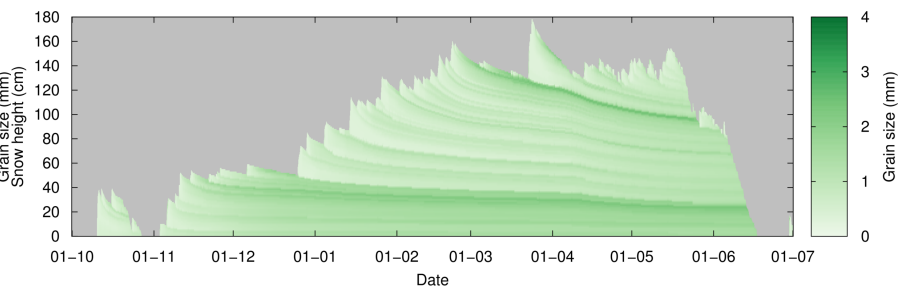

(j) 2013-2014

Figure S22: Grain size $(\mathrm{mm})$ for the snow height-driven simulations with the bucket scheme (left), and with RE-Y2012AM (right), continued. 